\title{
SEISMIC DAMAGE EVALUATION OF REINFORCED CONCRETE BUILDINGS WITH SLIT WALLS
}

\begin{abstract}
Purpose - The purpose of this paper is to investigate a reinforced concrete multi-storey building with dissipative structural walls. These walls can improve the behaviour of a tall multi-storey building. Our main objective is to evaluate the damage of a building with dissipative walls in comparison with that of the building with solid walls.

Design/methodology/approach - In this paper, a comparative nonlinear dynamic analysis between a building with slit walls and then the same building with solid wall is performed by means of SAP2000 software and using a layer model. The solution to increase the seismic performance of a building with structural walls is to create slit zones with short connections in to the walls. The short connections are introduced as a link element with multi-linear pivot hysteretic plasticity behaviour. The hysteretic rules and parameters of these short connections were proposed by the authors and used in this analysis. In this study, we propose to evaluate the damage of a building with reinforced concrete slit walls with short connections using seismic analysis.

Findings - Using the computational model created by the authors for the slit wall, a nonlinear dynamic analysis of a multistorey building with slit walls was done. From the results obtained, the advantages of the proposed structural typology are observed.

Originality/value - Using a simple computational model, created by the authors, that consume low processing resources and reduces processing time, a nonlinear dynamic analysis on high-rises buildings was done. Unlike other studies on slit walls with short connections, which are focused mostly on the nonlinear dynamic behaviour of the short connections, in this article we take into consideration the whole structural system, wall, connections and frames.
\end{abstract}

Key Words: high-rises building, reinforced concrete slit walls, layer model, nonlinear dynamic analysis, energy dissipation, damage index.

Article Classification: Research paper

\section{Introduction}

In a dual reinforced concrete structure, which is composed of frames and structural reinforced concrete walls, the frame provides support mainly for gravity loads while most of the resistance to lateral loads is provided by the structural walls. Such walls are used nowadays in many earthquake prone countries like Romania, Turkey, Chile, Mexico, China, Japan, USA, Peru etc. due to their high capacity of resisting lateral loads. In fact, both the shear walls and the frames participate in resisting the lateral loads resulting from earthquakes, the forces resisted by each one depending on their stiffness, modulus of elasticity, ductility, and the possibility to develop plastic hinges. Thus, the two structural systems must be designed to resist the total lateral load in proportion to their relative stiffness, maintaining the seismic vulnerability of the building within reasonable limits (Barbat et al. 2006; Lantada et al. 2009; Barbat et al. 2010; Barbat et al. 2011). Consequently, in earthquake prone areas, the designer should avoid the brittle failure of the structures by providing them sufficient ductility to assure inelastic deformations without the failure of the building under the action of strong seismic loads. A design condition of ductile reinforced concrete walls is that the failure of critical zones has to occur due to bending moment, assuring, in this way, high quantity of hysteresis energy dissipated by the wall and also stable hysteresis behaviour. Obviously, the structural walls with limited ductility should be avoided, because they have a brittle failure.

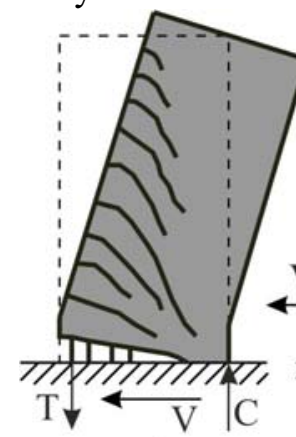

a)

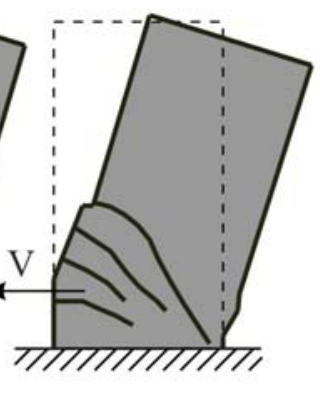

b)

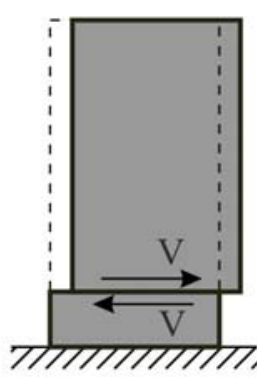

c)

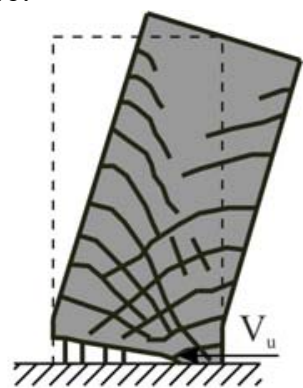

d)

Fig. 1. Failure of solid structural walls: a) flexural failure, b) horizontal tension, c) sliding of construction joint, d) sliding on flexural cracks 
Figure 1 shows types of failures in solid structural walls (Paulay and Priestley, 1992). Thus, Fig. 1a shows a flexural failure with a plastic hinge zone at the base of the wall. Fig. 1b shows diagonal tension in the reinforced concrete wall which lead to severe cracking of concrete requiring web reinforcement to absorb the horizontal shear force. Fig. 1c shows sliding failures along the construction joint and Fig. 1d shows rotation due to a construction joint. The most desirable is the flexural failure for which, with proper detailing, the wall can exhibit good strength and ductility without excessive drift or collapse. The solid structural wall can be weakened in a pre-defined zone along the height in order to create here a failure zone (Barbat and Bozzo 1997, Oller and Barbat, 2006; Faleiro et al. 2008) (Fig. 2). If the wall damages first in this zone, its strength and stiffness decreases suddenly and the wall become more slender and ductile.

Design of reinforced concrete structural walls for seismic resistance implies designing to resist axial forces, bending and shear. Boundary members to confine the concrete in compression regions, where stresses due to overturning are high, may be required. These members require transverse reinforcement capable of providing compression ductility through confinement, but they need not to resist all the vertical forces.

The design philosophy of a reinforced concrete wall requires that flexural yielding occurs in predetermined flexural hinging regions and brittle failure mechanisms will be precluded (diagonal tension, sliding hinges, local buckling). The design philosophy for walls is to ensure a ductile, flexural failure mechanism and preclude all brittle mechanisms. If there is a high compression demand at the edges of the walls, boundary elements may be required (CR 2-1-1.1, 2005, P100-1, 2006)

It has been observed that, in a tall structural wall, plastic hinges appear only at the base of the wall, the rest of the wall remaining undamaged. The alternative solution which overcomes this drawback consists of creating a slit zone with short connections introduced into the wall structure. The slits are complete breaks in concrete and reinforcements in order to change the solid structural reinforced concrete wall to a series of flexural wall-columns. Thus, the deflection capacity of the wall is larger, adequate to be used in high-rise buildings (Baetu el al, 2014). The width of the slit zone is less than $5 \mathrm{~cm}$ and the short connections can be displayed at various distances and with various heights in order to control their failure. This solution assures

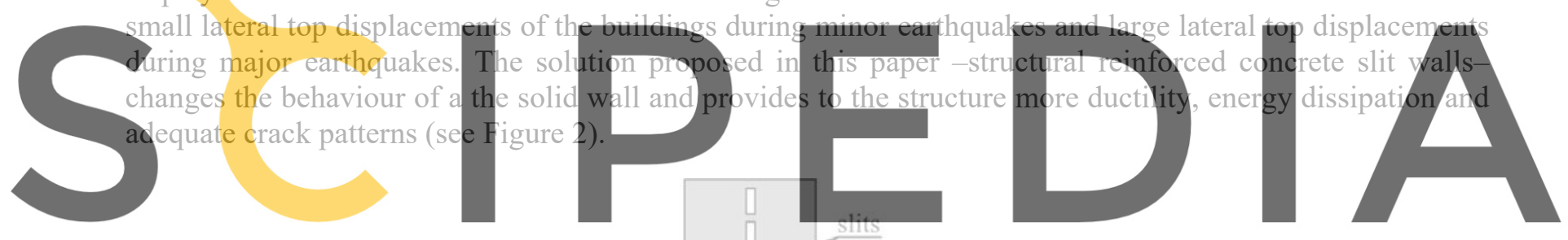

Register for free at https//www.scipedia.com to download the version without the watermark

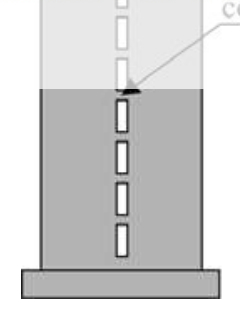

Fig. 2. Cast-in situ slit wall with a slit zone with short connections (Kwan et al., 1999)

We consider that these types of structural walls could be successfully used in seismic areas, especially in the case of soft soils and deep-focus earthquakes, case in which the predominant periods of the ground motion can be higher than 1s. This is the case, for example, of many seismic areas of Romania. The use of slit walls in high-rise buildings produces a sudden decrease of stiffness during strong ground motions, increasing the natural period of the building and avoiding, thus, resonance. With this solution, the seismic demands can be significantly reduced and an economical design can be reached.

In this article we consider the nonlinear behaviour of both the wall and the connections. The main objective is to evaluate numerically and to compare the damage of a building with slit walls considering the cases of nonlinear behaviour and of perfectly stiff walls. With this aim, we use a computational model developed by Baetu et al (2014) to study the nonlinear dynamic behaviour of multi-storey reinforced concrete buildings with slit walls with short connections subjected to strong ground motions. A 20 levels building with earthquake resistant design with a dual structure is analysed and discussed. A detailed nonlinear structural analysis of this building is performed. The same building is then modified into a building with slit walls with short connections, in order to study the improvement if its seismic behaviour when 
compared with that of the original building. The slit walls inserted in this building are the same slit walls that were studied by Baetu et al. (2014). A dynamic nonlinear analysis of both buildings is performed with the SAP2000 code using a layered finite element model for both the structural slit and the ordinary walls. The hysteretic behaviour of the short connections was simulated using the model developed and calibrated by Baetu et al. (2014). The dynamic analysis of the buildings allowed to calculate the dissipated hysteretic energy and to obtain the global seismic damage index of Park and Ang (1985). The computational model developed in this article is used to perform analyses on a set of relevant cases illustrating the application of the model and comparing the obtained results; conclusions useful for future research on the seismic behaviour of buildings with slit walls are finally obtained.

\section{The computational model}

\subsection{Material definition}

The layers of the confined and the unconfined C32/40 concrete and of the steel are defined by using the constitutive laws that describe the stress-strain relationships of the materials under cyclic behaviour (Baetu et al, 2014). The monotonic envelope curve of concrete follows the Takeda hysteretic model and the stress-strain curve of the steel follows the kinematic hysteretic model, both of them being predefined in SAP2000. The multilinear isotropic stress-strain curve for unconfined concrete is computed with the equations proposed by Desayi and Krishnan in 1964 (Kachlakev et al., 2001) and, for the confined concrete, the strength and deformations have been increased according to SR EN 1992-1-1:2004. The stress-strain relationships under cyclic behavior for confined and unconfined concrete and for steel can be found in Baetu el al. (2014).

2.2 Description of the layered shell element for the structural walls analysis

The seismic damage analysis of the reinforced concrete walls is performed by using a layered shell

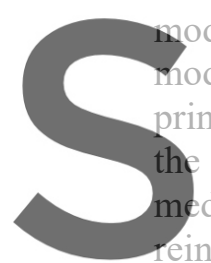

odel which considers the

odel, useful to simulate

inciples of the mechanic

median plane or perpe

edian plane (SAP2000).

einforcement bars are inserted within one or more
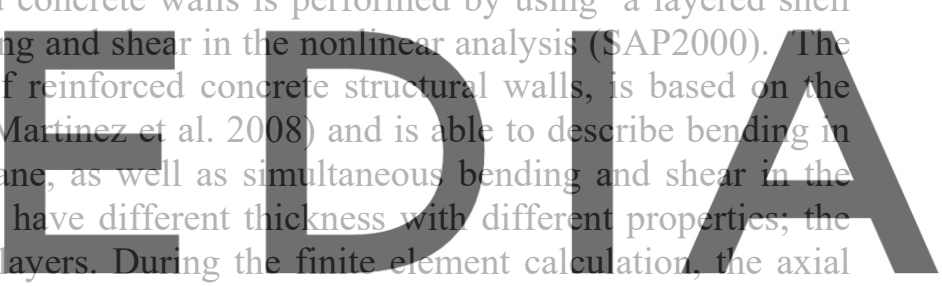

strain and curvature of the middle layer is obtained in all the elements and the strains and the curvatures of

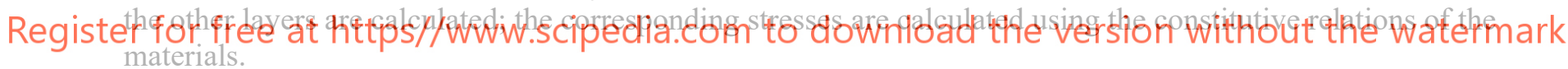

The reinforcements disposed in different directions are introduced in a single layer. If the amount of the steel reinforcement distributed in longitudinal and transversal directions of the concrete is the same, the layer of steel is introduced as isotropic. But, if the amounts of steel in the two directions are different, a reinforcement layer with two orthotropic main axes is used (Miao et al., 2006, Baetu and Ciongradi, 2011). In the model used herein, five layers have been defined, one corresponding to the confined and unconfined concrete in the wall and its boundaries and four corresponding to the reinforcement in the horizontal and vertical directions on both sides of the wall section (Fig. 3) (Sap2000 V14 Help).

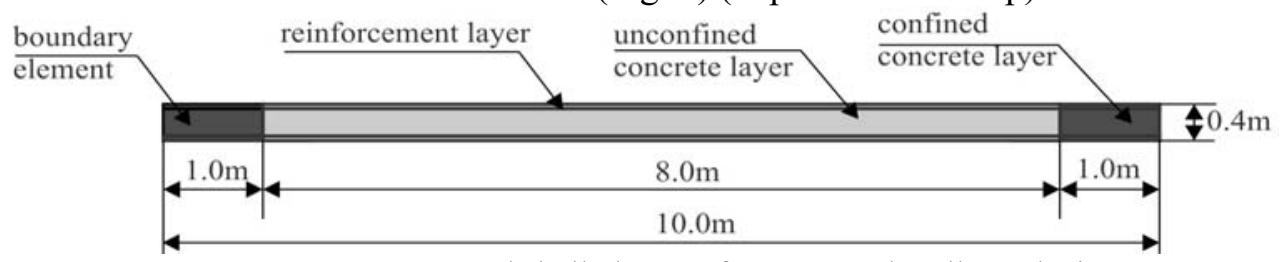

Fig. 3. Layered shell element for structural walls analysis

\subsection{Hysteretic model of the short connections}

The short connections of reinforced concrete structural slit walls, which are key elements dominated by shear, have been introduced in SAP2000 (Fig. 4) as link elements with multi-linear pivot hysteretic plasticity property (Lepage et al., 2006). The model is capable to simulate the pinching effect, is similar to the multi-linear constitutive model of Takeda but has additional parameters which control the degradation of the hysteretic behaviour (Baetu et al. 2014). 


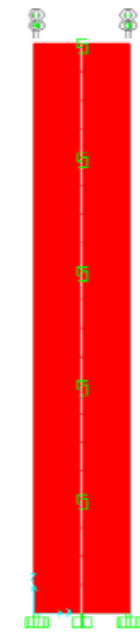

Fig. 4. Slit wall with five short connections analyzed in SAP2000

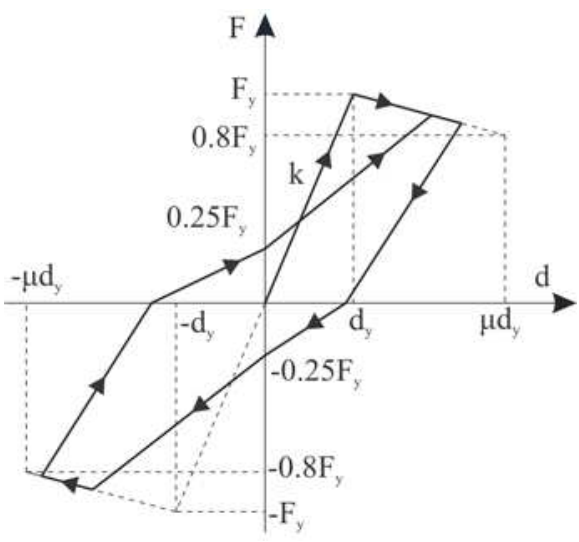

Fig. 5. Hysteretic model for a reinforced concrete short beam (Kwan et al., 1999)

The hysteretic force-displacement curve with stiffness and strength degradation and pinching effect is shown in Fig. 5, where $\mathrm{k}$ is the initial stiffness, $\mathrm{F}_{\mathrm{y}}$ is the yield force, $\mathrm{d}_{\mathrm{y}}$ is the yield displacement and $\mu$ is the ductility.. The construction of this hysteretic curve begins with the monotonic force-displacement curve of a short connection and is obtained with the finite element code ANSYS 12 by using the pivot hysteretic rules for loading and unloading (Baetu et al., 2014). The hysteretic parameters required are obtained from static experimental tests and from cyclic analyses of short beams dominated by shear (Kwan et al., 1999, Gedik et al., 2011, Zhao et al., 2004). The ductility is approximately 3 from the experimental static curve

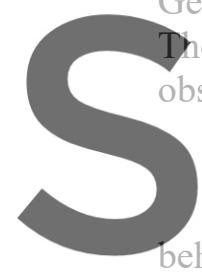

observed if the beam is well reinforced

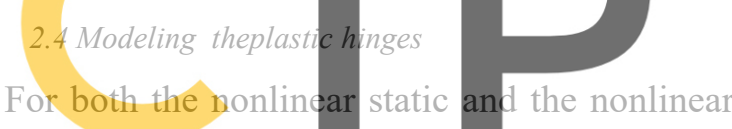

For both the nonlincar assigning concentrated
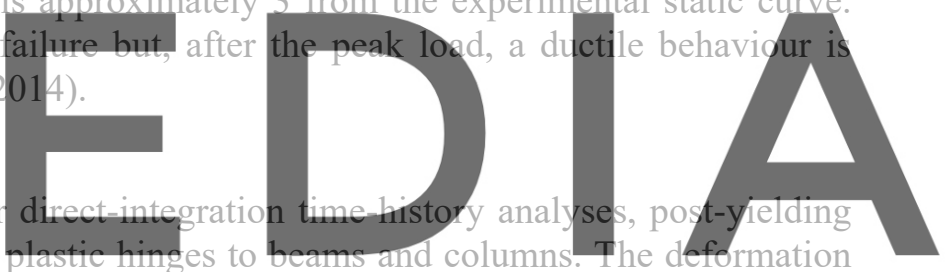

beyond the elastic limit occurs only in the predefined hinges placed in discrete locations, while the rest of the

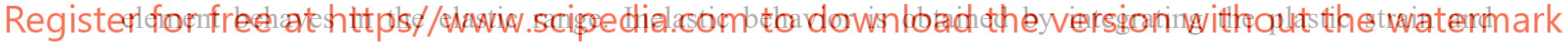

plastic curvature which occurs within the predefined hinge length. Multiple hinges may also coincide at the same location. Plasticity is associated with force-displacement behavior (axial and shear) and with the moment-rotation behavior (torsion and bending). Modeling the strength loss is discouraged, in order to mitigate load redistribution (which may lead to progressive collapse) and to ensure numerical convergence. For the columns we used the P-M2-M3 plastic hinges which can capture coupled axial and biaxial-bending behavior while for the beams we used the M3 plastic hinge which can capture only the bending behavior (Sap2000 V14 Help).

In the literature there are different proposed models to calculate the length of the plastic hinges. In this article, the calculation of the length of plastic hinges is made according to the model of Paulay and Priestley (1992)

$$
L_{p}=0.08 L+0.022 d_{b} f_{y}
$$

where $L$ is the distance from the critical section of the plastic hinge to the point of contra flexure, $f_{y}$ and $d_{b}$ are the yield strength and the diameter of longitudinal reinforcement bar, respectively.

\section{Description of the studied structures and of their models}

The case study refers to a multi-storey building in a seismic area whose boundary walls are considered with slits and also without slits. The building is located in the city of Iaşi, Romania, with the following site characteristics: design ground acceleration $\mathrm{a}_{\mathrm{g}}=0.2 \mathrm{~g}$, control period $\mathrm{T}_{\mathrm{c}}=0.7 \mathrm{~s}$, ductility class $\mathrm{H}$ (high) and importance factor $\gamma_{\mathrm{I}}=1$ which means that the building is residential (P100-1/2006) (the buildings are classified by the Romanian seismic code in clases of importance according to the human and economic consequances of a major earthquake and their importance in post-earthquake response actions). In order to 
perform the seismic analysis of this building the response spectrum method was used. The building has dual reinforced concrete structure and regular shape in plan and elevation. The seismic lateral loads applied upon the building are absorbed by the concrete core and, in the short direction, by the border walls. It has 20 levels with a height of $3 \mathrm{~m}$ each. In plan, the building has $31 \mathrm{~m}$ in length and $21 \mathrm{~m}$ in width (Fig. 6). The concrete used in the analysis is C32/40. The reinforcement used in the analysis is PC52 (with design strength 300 $\mathrm{N} / \mathrm{mm}^{2}$ ) for longitudinal and transversal reinforcement OB37 (with design strength $210 \mathrm{~N} / \mathrm{mm}^{2}$ ) for stirrups. The fundamental period of the structure is $\mathrm{T}_{1}=1.077 \mathrm{~s}$. The dimensions of the cross section of the columns are $100 \times 100 \mathrm{~cm}$, the slab thickness is of $15 \mathrm{~cm}$ and, in the center, the building has two reinforced concrete cores for stairs and elevator with the dimensions $4 \times 7 \mathrm{~m}$ and $4 \times 4 \mathrm{~m}$, respectively; all the walls have the thickness of $40 \mathrm{~cm}$. The analysis was performed with the computer program SAP2000 and a thickness of the wall of 40 $\mathrm{cm}$ was obtained; the wall is reinforced with vertical rebars with diameter of $14 \mathrm{~mm}$ disposed at a distance of $15 \mathrm{~cm}$ and with rebars with diameter of $10 \mathrm{~mm}$ disposed at a distance of $15 \mathrm{~cm}$ (CR 2-1-1.1-2005, Baetu et al., 2010, Baetu and Ciongradi, 2012; Baetu, 2013).
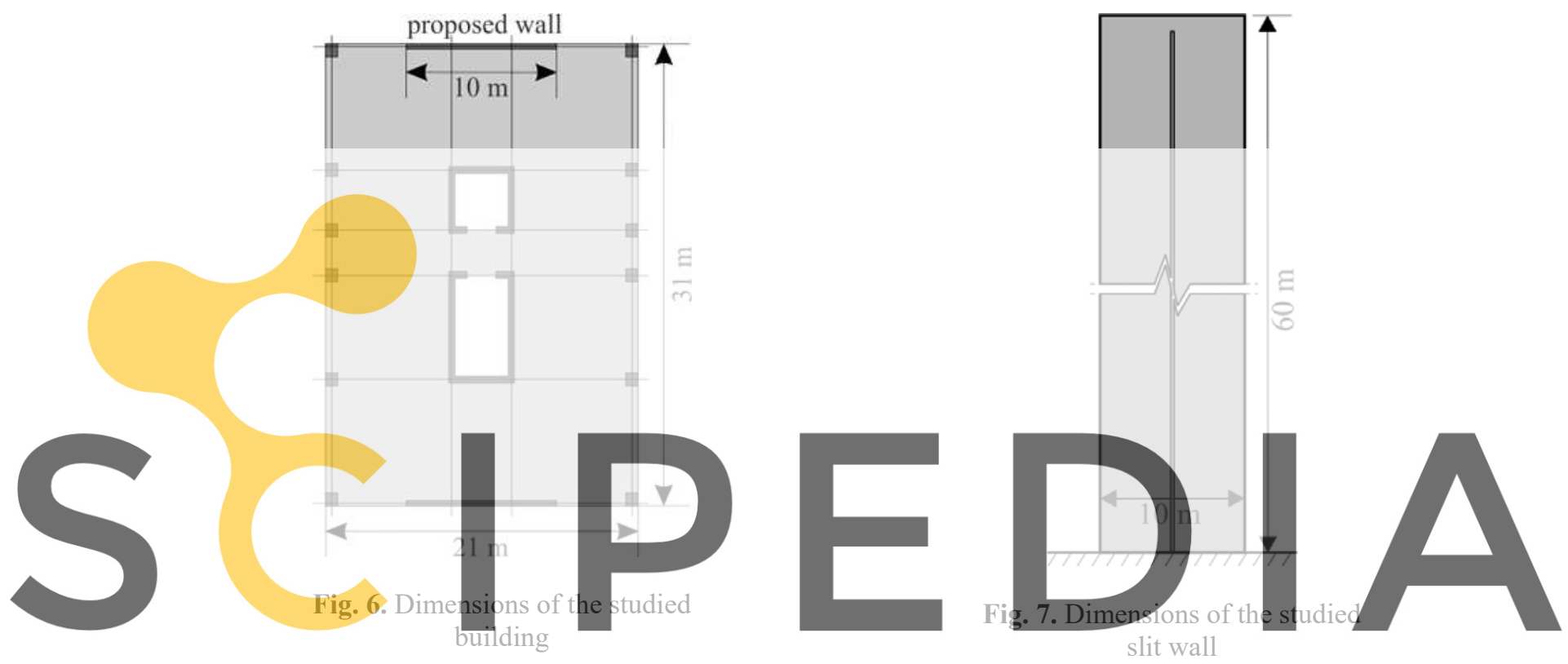

\section{Register for free at https//www.scipedia.com to download the version without the watermark The boundary elements were designed according to the Romanian standard CR 2-1-1.1-2005 in order} to reach a high level of ductility during a seismic event. There are five connections along the slit wall height disposed at equal length of $12 \mathrm{~m}$. The height of each connection is $0.40 \mathrm{~m}$ and the thickness of the slit is $5 \mathrm{~cm}$.

Comparative nonlinear static pushover analyses and nonlinear dynamic analyses were performed on the building with slit walls with five shear connections and on the building with solid wall.

With the purpose to reduce the influence of the plate on the slit zone and to allow the slip in this zone, a slit zone with the width of $5 \mathrm{~cm}$ and the length of $4 \mathrm{~m}$ was inserted in the plate. In this way, the plate is partially disconnected from the slit wall, as it can be seen in Fig. 8. 


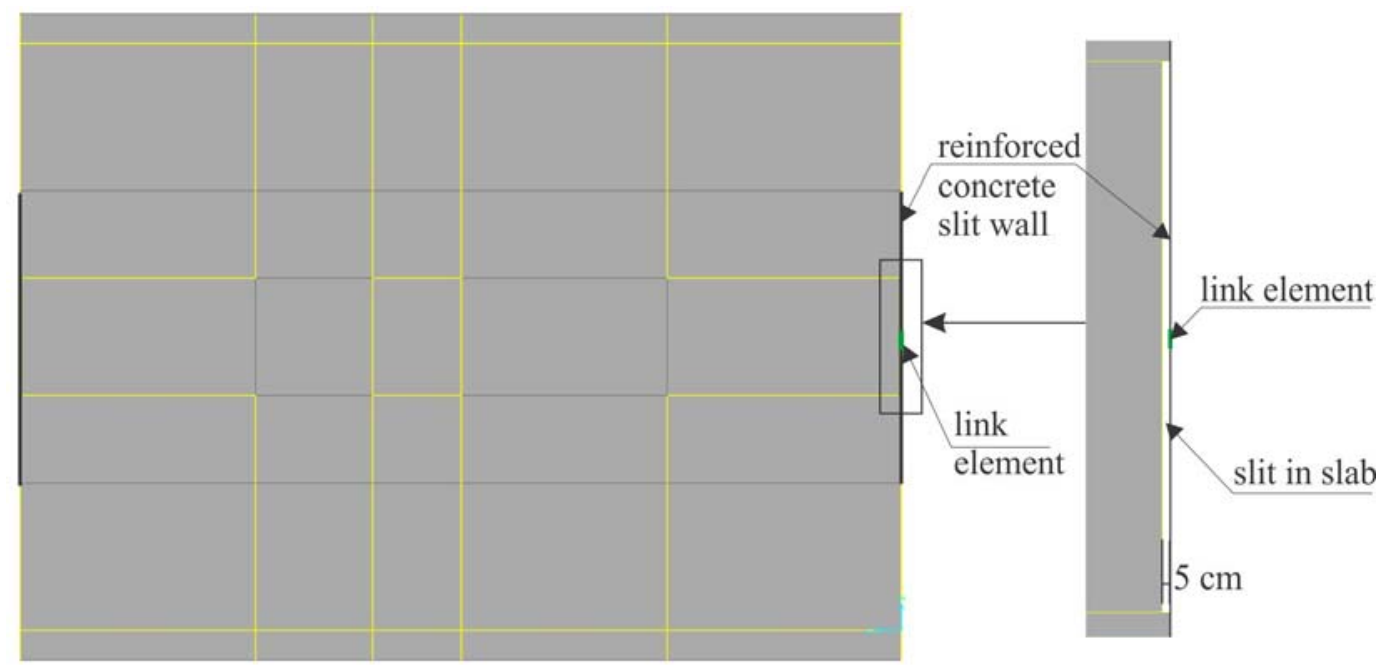

Fig. 8. - The plane of the studied building with slit walls

\section{Pushover curves of the studied buildings}

The damage index of Park\&Ang considers the structural damage as a linear combination between damage due to deformations and due to dissipated hysteretic energy at repeated cyclic loading $D I_{P \& A}=\frac{\delta_{m}}{\delta_{u}}+\frac{\beta}{\delta_{u} P_{v}} \int d E_{h}$
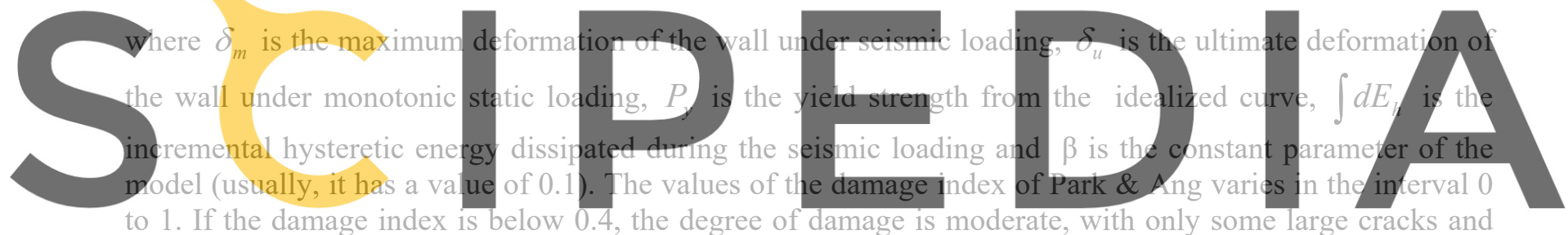

spalling of concrete in weaker elements and the building is repairable. Between 0.4 and 1, the degree of

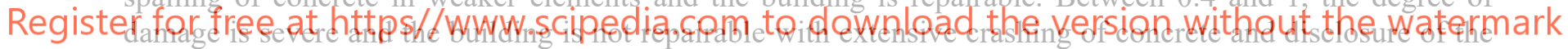

buckled reinforcement. Finally, if the damage index exceeds the value of 1 , the building collapses.

The damage model of Park\&Ang (Park and Ang, 1985, Valles et al., 1996, Vera, 2006, Vielma et al., 2009, Belarbi and Prakash, 2009, Vielma et al., 2010, Ghosh et al., 2011) takes into account the degradation due to the maximum incursion in the inelastic range and due to the cyclic deformations. The Park and Ang damage index equation is suitable for slender RC walls but there are some limitations for the walls dominated by shear (Vera, 2006). In the case of slit walls this damage index is adequate because the walls become very slender after the short connections fail. The value chosen for the parameter $\beta$ for the studied structural walls is 0.1 (Vera 2006). The direct application of the damage model on a structural element, a story or a building, requires determining the ultimate deformations of the corresponding element, story or building.

In order to calculate the damage index of Park and Ang, the ultimate displacement and the yielding force of the proposed buildings with slit walls and then with ordinary walls, nonlinear monotonic static analyses have been performed. The failure of the short connection causes strength degradation and large displacements of the wall and, as it can be seen on the pushover curve, the stiffness of the building with slit walls decreases suddenly very much and remains at this level until the displacement of $0.63 \mathrm{~m}$ is reached, when the building collapses. 


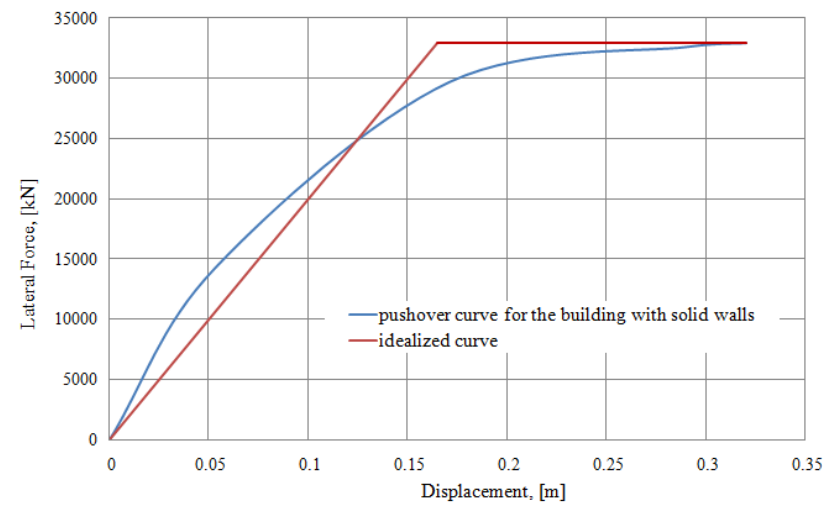

Fig. 9. Pushover and idealized curve for the proposed building with solid wall

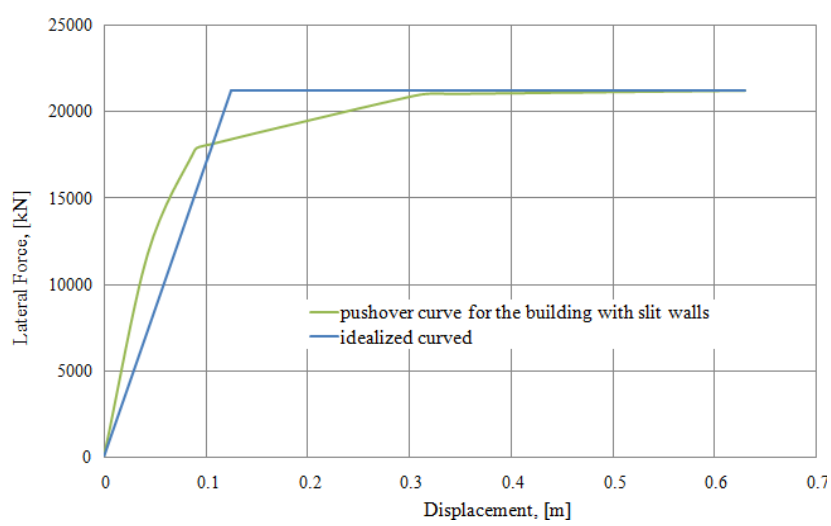

Fig. 10. Pushover and idealized curve for the proposed building with slit wall

Comparing the pushover curves of the structure with solid wall (Fig. 9) with that of the structure with slit wall (Fig. 10), we can observe that the solid wall fails at a higher lateral force, $32950 \mathrm{kN}$, and at a lower displacement, of $0.32 \mathrm{~m}$, while the slit wall fails at a lower lateral force, $21195 \mathrm{kN}$, and at a higher displacement, of $0.63 \mathrm{~m}$. From the pushover curves obtained for both analyzed buildings, it can be seen that the building with solid walls has a brittle failure while the building with slit walls has a ductile failure. It is obvious that the structure with dissipative walls has higher ductility and behaves better in seismic areas. Also, from this analysis, it is noticed that the stiffness of the structure with dissipative walls is identical to that with solid walls till the shear connections start to fail. The yielding force, the yielding displacement and the ultimate displacements are shown in Table 1.

Table 1. The parameters required to calculate the Park\&Ang damage index
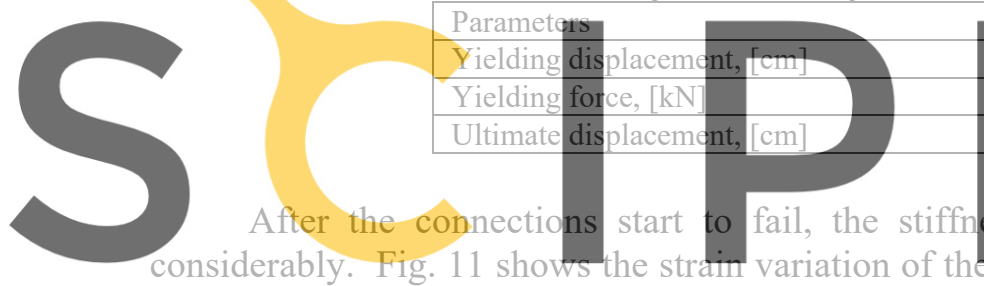

After the connections start to fail, the stiffin
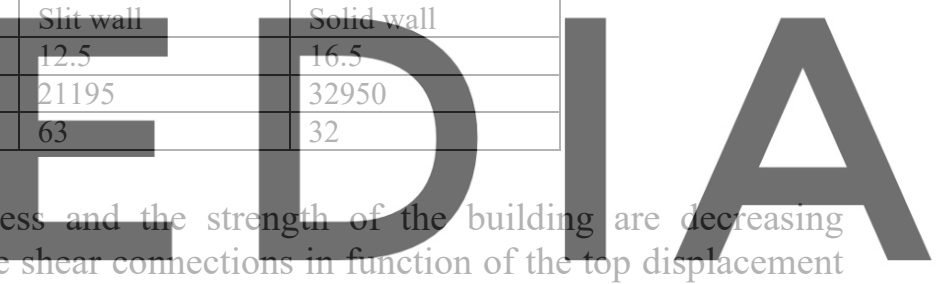

of the structure. This graphic shows the lateral displacement of the structure at which the shear connections

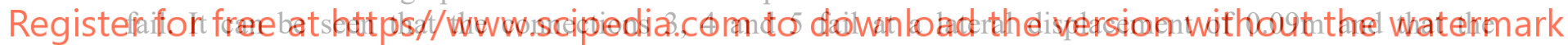

connections 1 and 2 fail at a lateral displacement of $0.31 \mathrm{~m}$ (fig. 11, fig. 12). Practically, the failure of all connections happens at a lateral displacement close to the ultimate lateral displacement of the structure with solid walls.

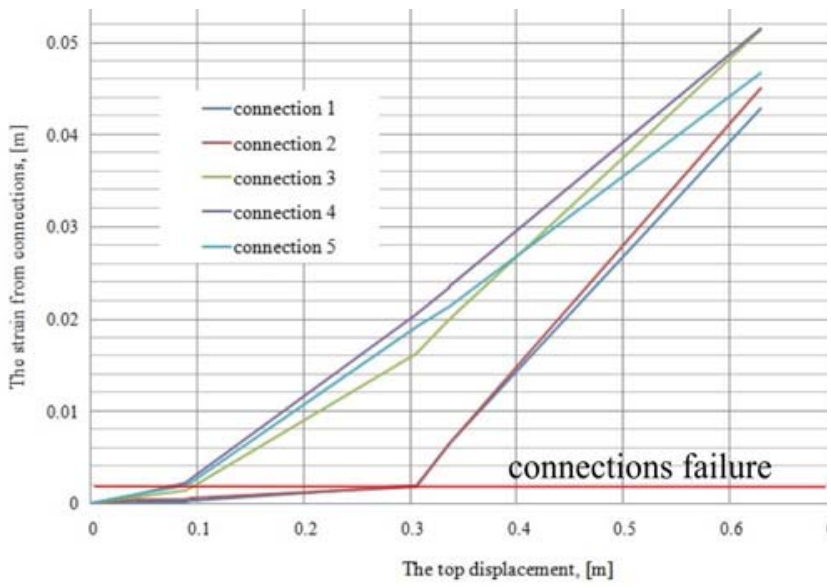

Fig. 11 -Variation of connections strain in function of the top displacement of the structure

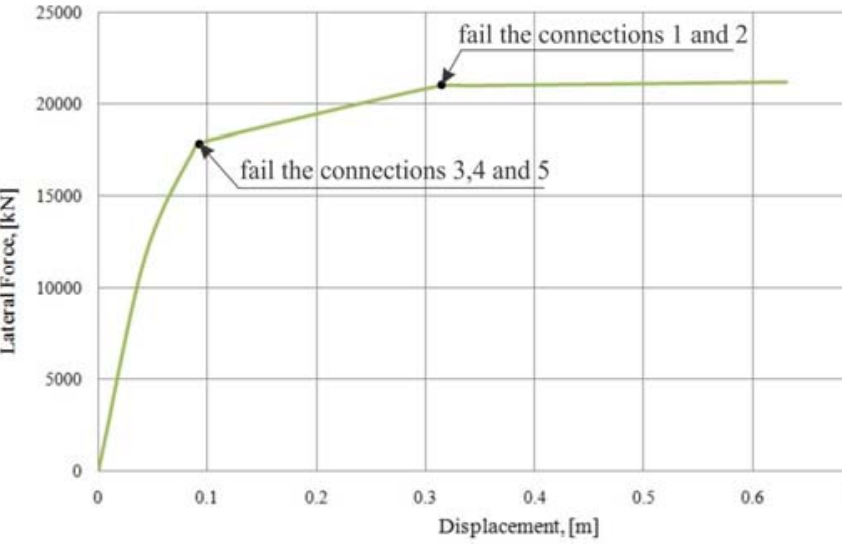

Fig. 12 -Failure of the short connections

The ATC-40 and FEMA-237 documents have developed modeling procedures, acceptance criteria and analysis procedures for pushover analysis. These documents define force-deformation criteria for hinges 
used in pushover analysis. As shown in Fig. 13, five points labeled A, B, C, D, and E are used to define the force deflection behavior of the hinge and three points labeled IO, LS and CP are used to define the acceptance criteria for the hinge (IO, LS and CP stand for Immediate Occupancy, Life Safety and Collapse Prevention respectively) (Sap2000 V14 Help).

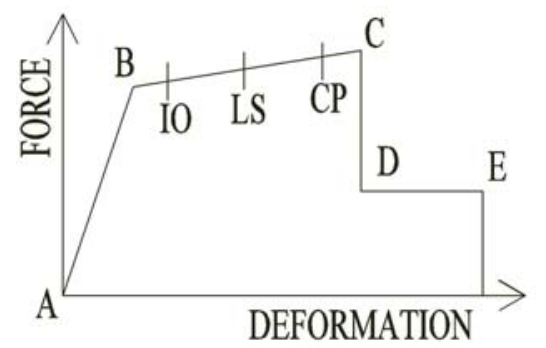

Fig. 13 - Nonlinear behavior curve of hinges (IO - Immediate Occupancy, LS - Life Safety, CP - Collapse Prevention, $\mathrm{AB}$ - elastic range, point $\mathrm{B}$ - plastic hinge development (yielding of the element), $\mathrm{CD}$ - strength degradation of the plastic hinge, point $\mathrm{E}$ - failure of the plastic hinge)

Analysing the plastic hinges developed in the columns and beams of the building with solid walls in the last step of the pushover analysis (Fig. 14), it can be observed that most of the plastic hinges correspond to level B of damage (i.e. elastic behaviour) and to the level IO of damage (i.e. immediate occupancy). Thus, the acceptance criteria is that of immediate occupancy, and only few plastic hinges in the columns of the levels 11 and 12 reach the damage level $\mathrm{C}$ and exceed the acceptance criteria CP (i.e. collapse prevention). It is obvious that most of the lateral loading is absorbed by the peripheral walls and by the two reinforced concrete cores disposed in the centre of the building. Practically, the collapse of the structure occurs once the reinforced concrete walls collapse. The columns and the beams do not influence on the collapse of the building and most of

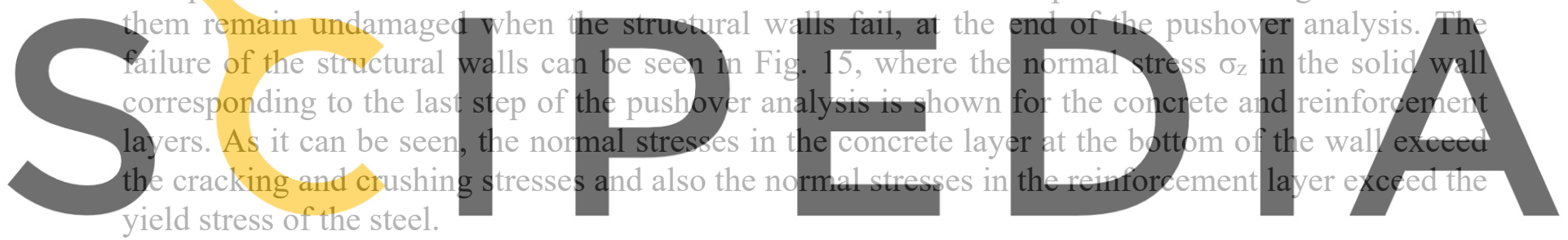

yield stress of the steel.

In the last loading step of the pushover analysis of the building with slit walls, it can be observed that

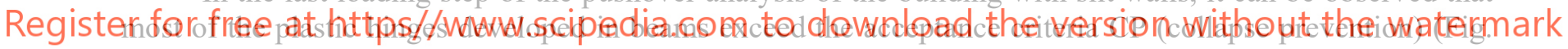

16). That is, the collapse of the dual structure is caused both by the walls and the beams failure. The failure of the slit walls can be seen in Fig. 17, where the normal stresses in the last loading step of the pushover analysis are shown for the concrete and reinforcement layers. The normal stresses exceed the cracking, crushing and yield limits for both layers of concrete and reinforcement.
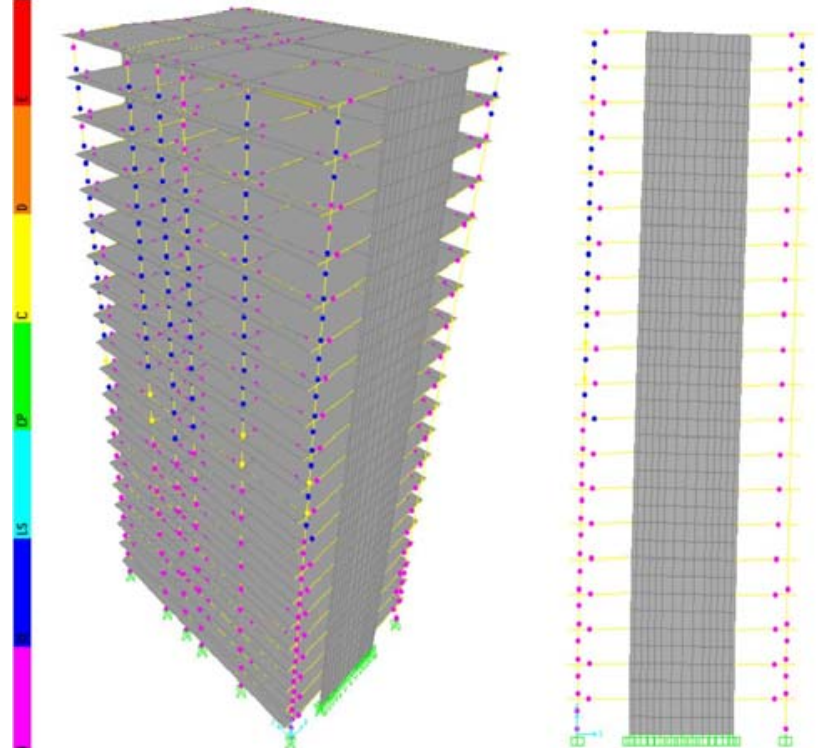

Fig. 14. - The plastic hinges which appear in the columns

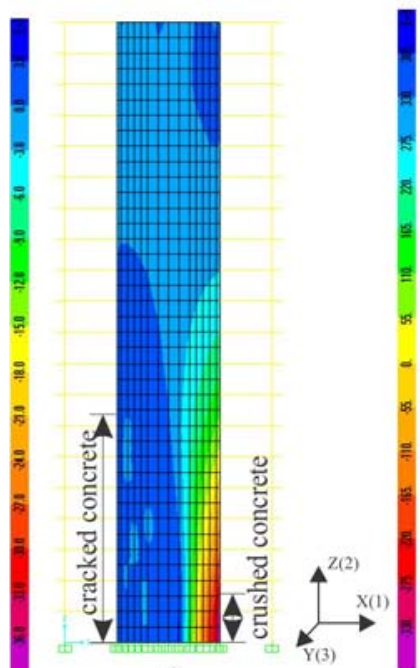

a)

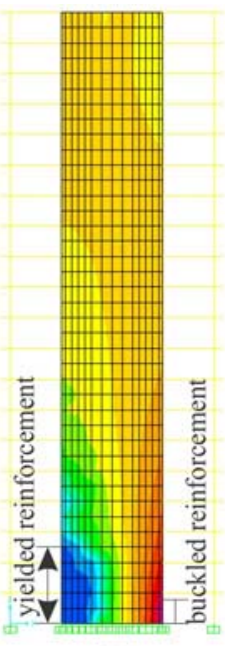

b)

Fig. 15. - Normal stresses $\sigma_{z}$ in the solid wall at the last step of pushover analysis $\left(\mathrm{kN} / \mathrm{m}^{2}\right)$ : a) in 
and the beams of the building with solid walls, in the last step of the pushover analysis the concrete layer and b) in the reinforcement layer
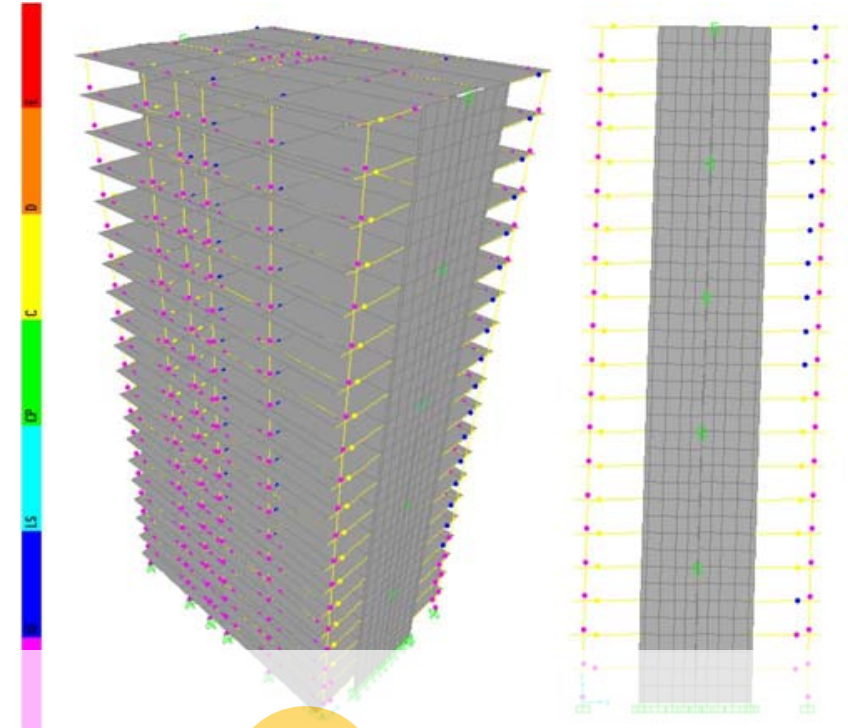

Fig. 16. -Plastic hinges in the columns and beams of the building with slit walls corresponding to the last step of pushover analysis
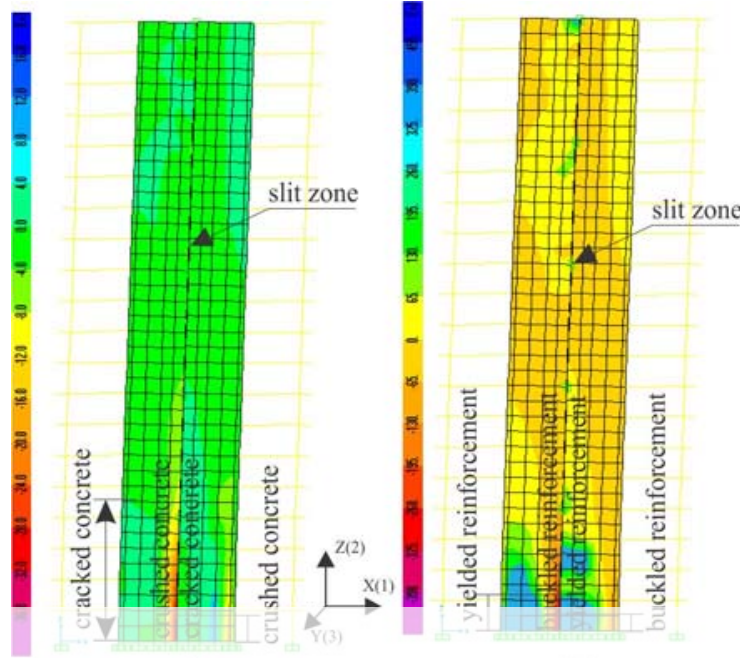

b)

Fig. 17. - Normal stresses $\sigma_{z}$ in the solid wall at the last step of pushover analysis $\left(\mathrm{kN} / \mathrm{m}^{2}\right)$ : a) in the concrete layer and b) in the reinforcement layer

Two more parameters are needed to calculate the Park\&Ang damage index, that is, the maximum

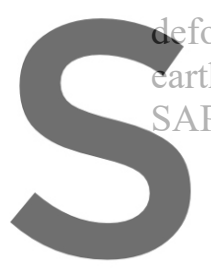

\section{formation of the wall unde}

AP2000 with the layered m

5 Dynamic analysis
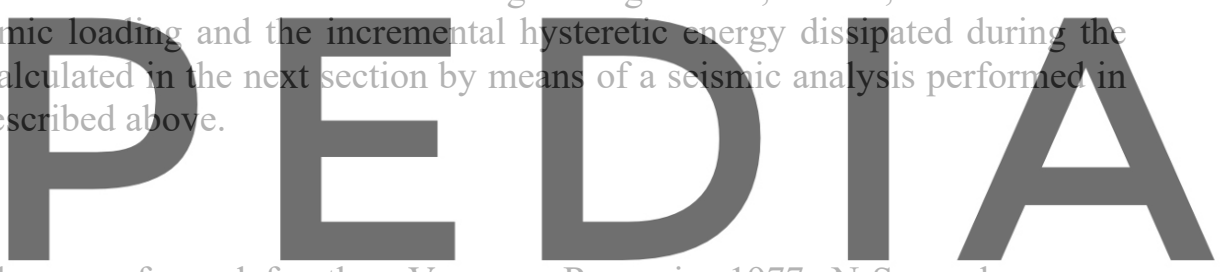

The dynamic analysis has been performed for the Vrancea, Romania, 1977, N-S accelerogram,

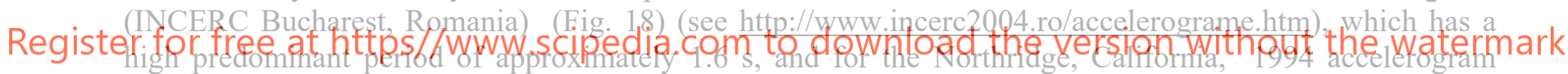

(Sylmar Converter, Los Angeles, USA) (Fig. 19) (see http://peer.berkeley.edu/nga/search.htm), which has a low predominant period, of approximately $0.7 \mathrm{~s}$ (Egozcue et al 1991). The building with shit walls was studied in two regions with different earthquake characteristics in order to establish the differences which may occur in their failure mode, the energy dissipation and the damage index. The masses of the structure were defined from the loads imposed on the structure where the permanent loads were multiplied with the factor 1 and the live loads and snow load were multiplied with the factor 0.4 .

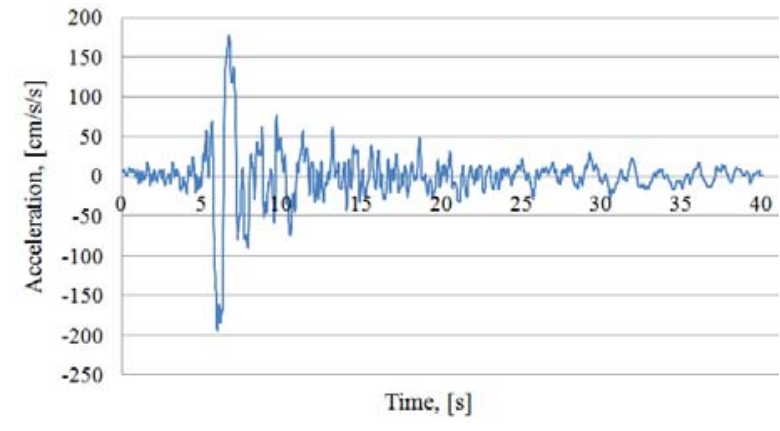

Fig. 18. Vrancea, Romania, 1977, N-S component of the acceleration

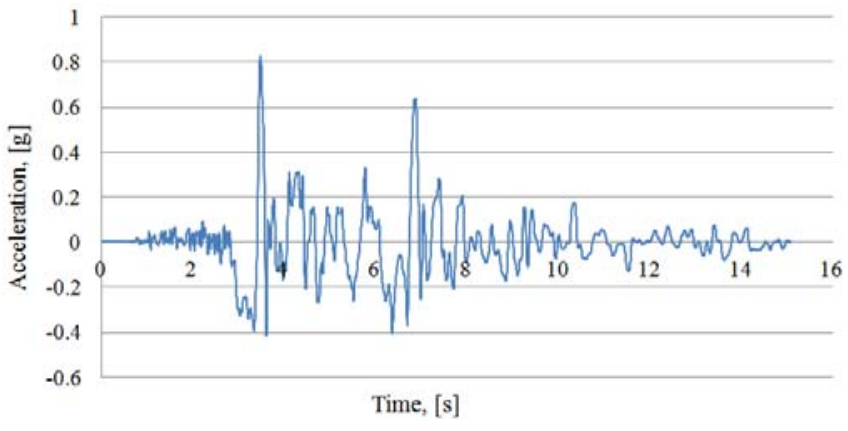

Fig. 19. Northridge, California, 1994 accelerogram

A relation between the peak ground acceleration, PGA, and the damage index, DI, was obtained by performing dynamic analyses s for both earthquakes. The earthquakes were scaled starting from a very small value of the peak ground acceleration, for which the walls behave in the elastic range, till big peak ground 
acceleration, for which the connections fail and the wall splits in two parts. Within the case of the Vrancea $1977 \mathrm{~N}-\mathrm{S}$ earthquake, the PGA values used in the analysis were $0.1 \mathrm{~g}, 0.2 \mathrm{~g}, 0.3 \mathrm{~g}, 0.4 \mathrm{~g}, 0.5 \mathrm{~g}$ and for the analysis with Northridge 1994 earthquake, the PGAs used into the analysis were $0.2 \mathrm{~g}, 0.4 \mathrm{~g}, 0.6 \mathrm{~g}, 0.8 \mathrm{~g}, 1.0 \mathrm{~g}$.

The comparative hysteretic behaviour of the buildings with slit and solid walls as well as the dissipated hysteretic energies obtained by performing their dynamic analysis for the accelerogram of the N-S component of the Vrancea, 1977, earthquake scaled at a PGA of 0.2g, are shown in Fig. 20 and Fig. 21, respectively. Similar results but obtained for the accelerogram of the Northridge 1994 earthquake scaled at a PGA of $0.4 \mathrm{~g}$, are shown in the figures 22 and 23 . When the connections start to fail, the slit walls begin to dissipate more energy and the difference between the energy dissipated in the two cases increases. Obviously, before the failure of any connection, the behaviour of these two buildings (with slit walls and with solid walls) is almost identical and the dissipated energy is the same. This demonstrates that the slit wall has a higher energy dissipation capacity than the solid wall. The area enclosed by the hysteretic loop represents the amount of energy that the structure has to dissipate through inelastic response. If the structure can dissipate the hysteretic energy demanded by the earthquake, it will survive.

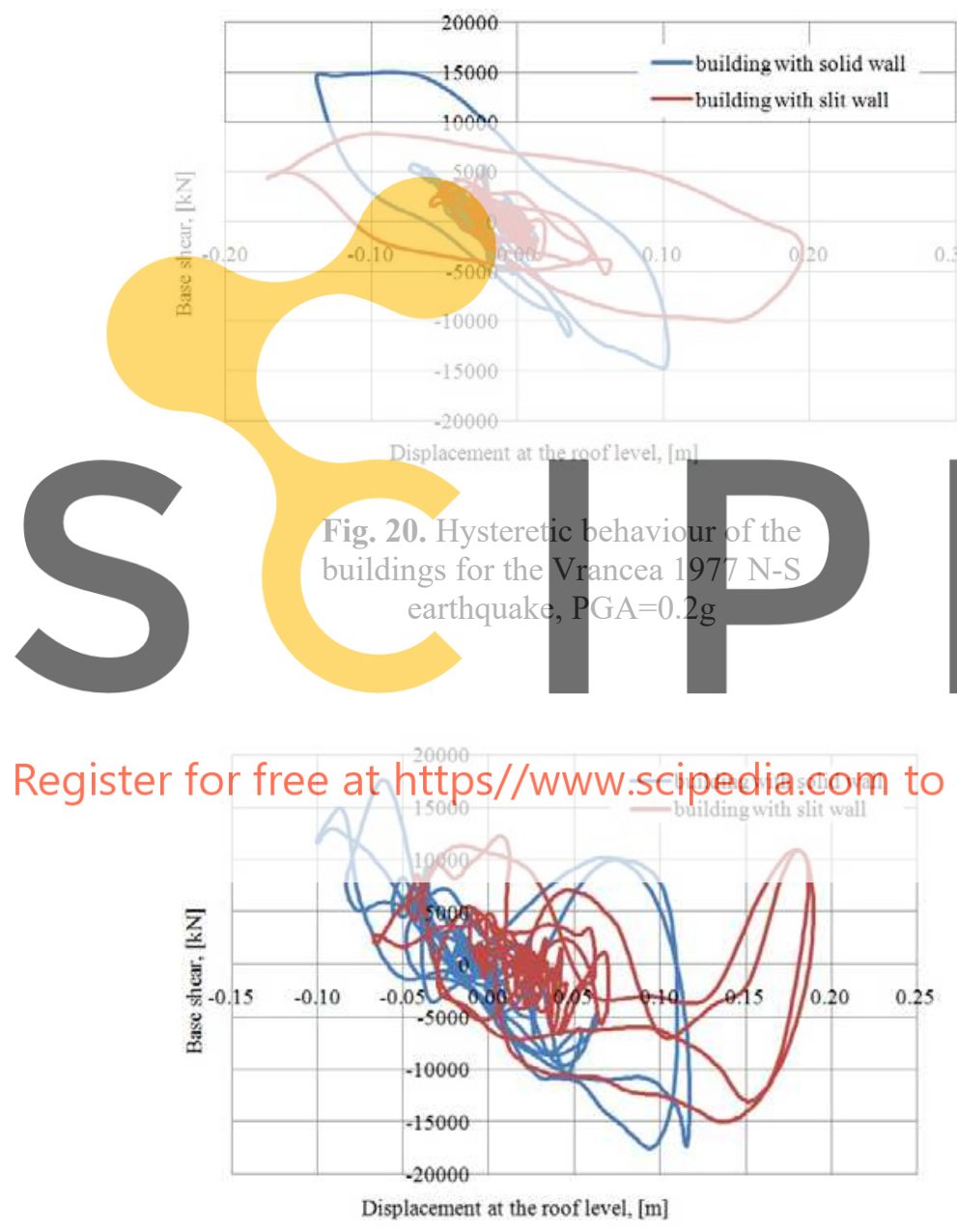

Fig. 22. Hysteretic behaviour of the buildings for the Northridge 1994 earthquake, $\mathrm{PGA}=0.4 \mathrm{~g}$

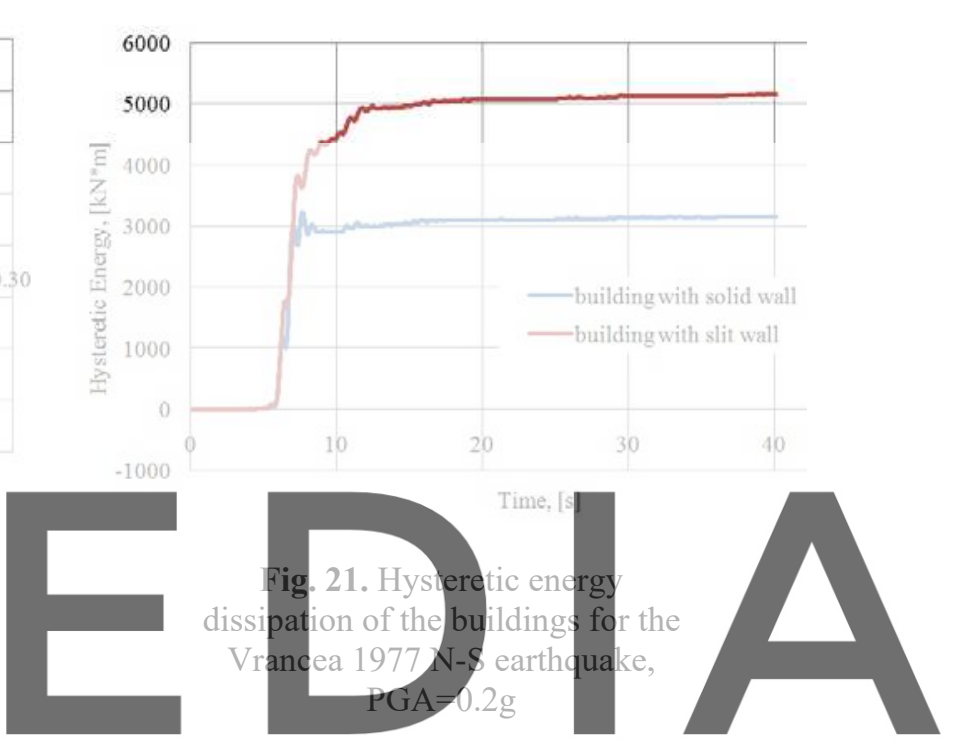

${ }^{6000}$ oad the version without the watermark

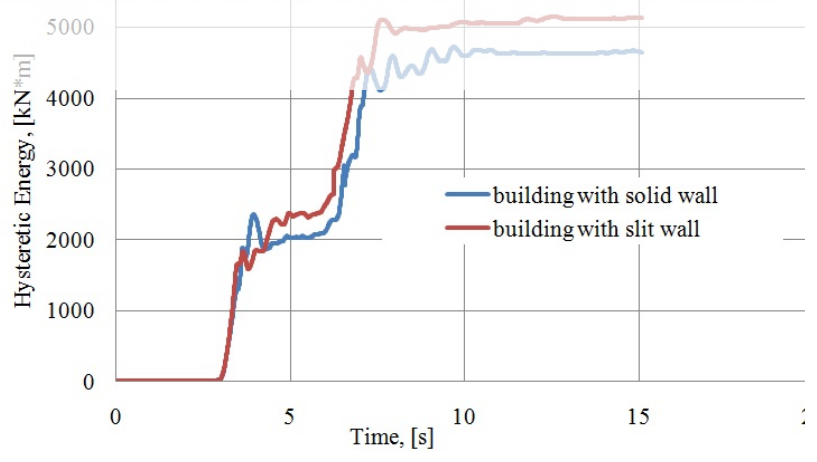

Fig. 23. Hysteretic energy dissipation of the buildings for the Northridge 1994 earthquake, $\mathrm{PGA}=0.4 \mathrm{~g}$

The comparison between the damage results obtained for the buildings with slit and with solid walls for both earthquakes considered in the analysis allows establishing a relationship between the damage index and the PGA (figures 24 and 28) and between the dissipated hysteretic energy and the displacement at the roof level (figures 25-29). The mentioned results are obtained by increasing the PGA and by scaling adequately the accelerograms for these PGA, until the collapse of the walls is reached. Two comparisons are made, one between the spectral accelerations (Fig. 30) and the other one between the displacement timehistory (Fig. 31) at the top of the studied buildings subjected to the Vrancea, 1977, N-S component of the earthquake, scaled for a PGA of $0.2 \mathrm{~g}$. Also, the same comparisons are done for the buildings subjected to the 
Northridge 1994 earthquake, scaled for a PGA of 0.4g (figures 32 and 33). It is important to note that for these PGAs (of $0.2 \mathrm{~g}$ for Vrancea and of $0.4 \mathrm{~g}$ for Northridge) the short connections fail for both earthquakes.

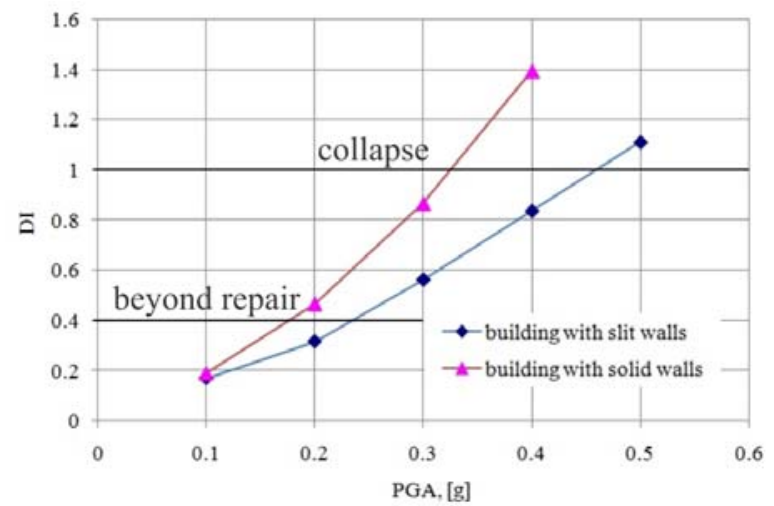

Fig. 24. The variation of DI with PGA for the Vrancea 1977 N-S earthquake

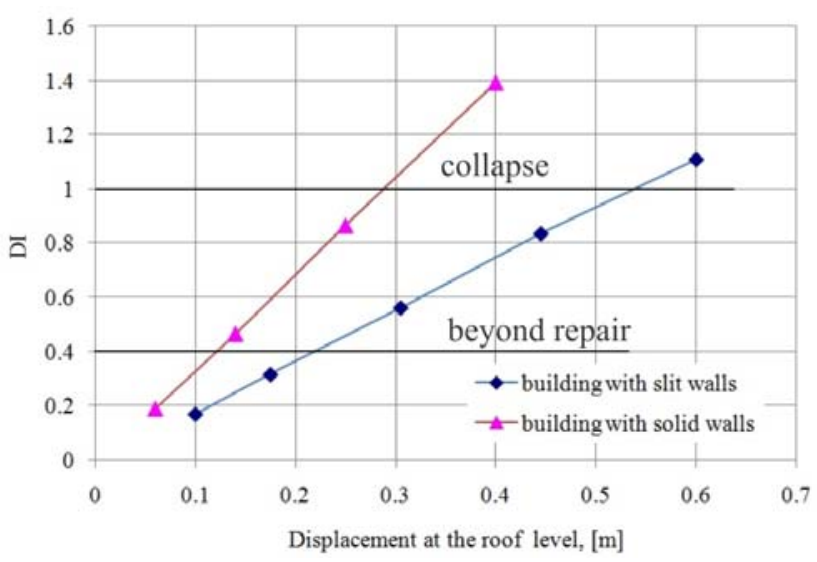

Fig. 26. The variation of DI with displacement at the roof level for the Vrancea 1977 N-S earthquake

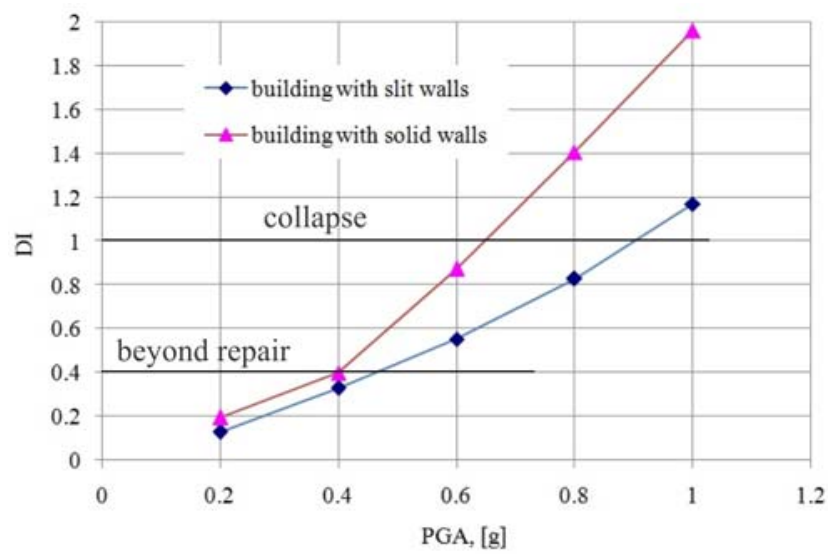

Fig. 28. The variation of DI with PGA for the Northridge 1994 earthquake

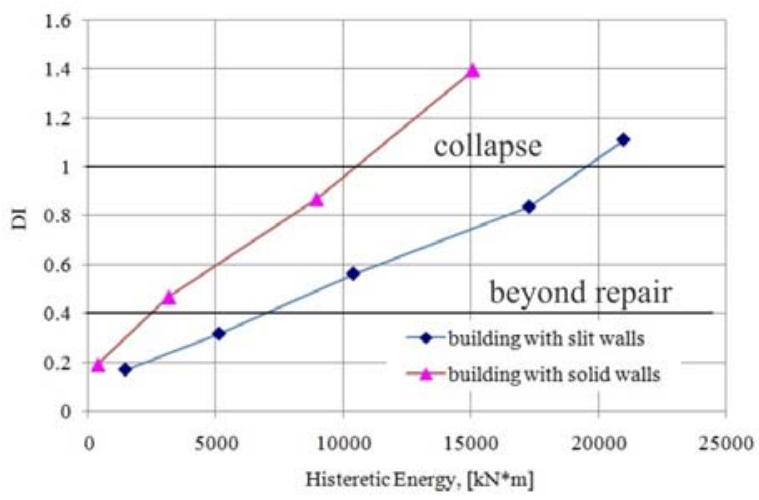

Fig. 25. The variation of DI with hysteretic energy dissipated for the Vrancea 1977 N-S earthquake

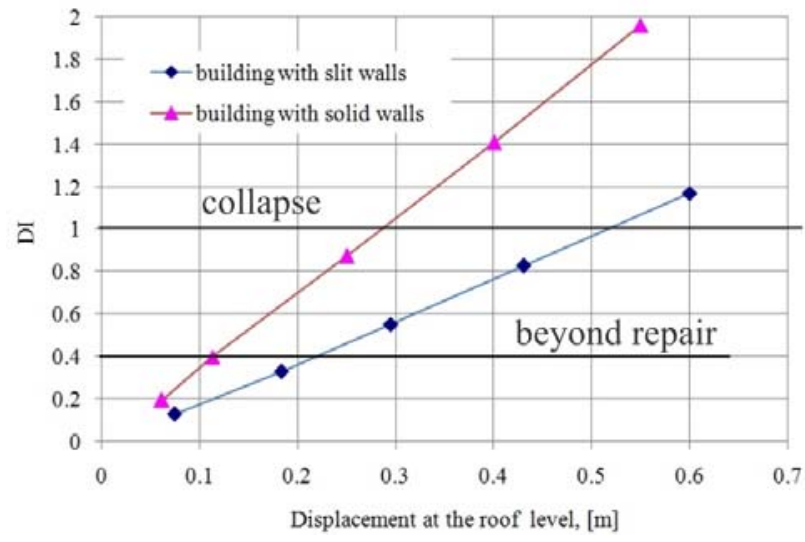

Fig. 27. The variation of DI with displacement at the roof level for the Northridge 1994 earthquake

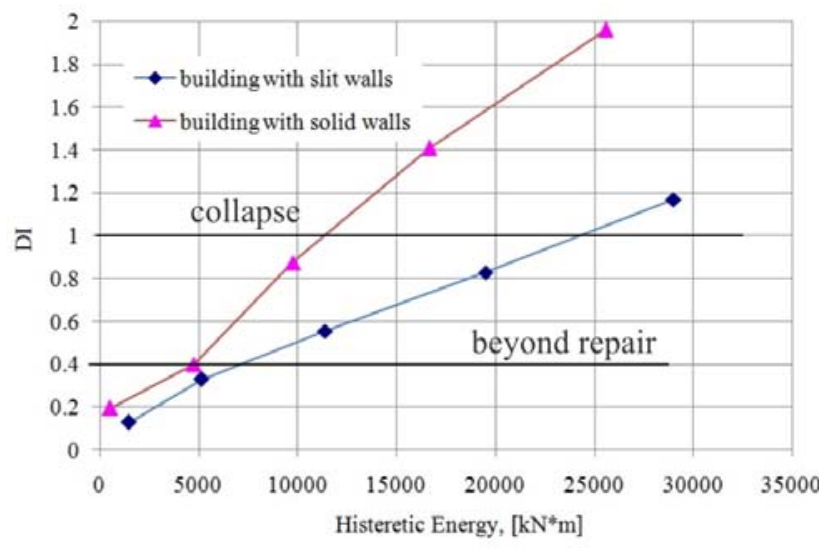

Fig. 29. The variation of DI with hysteretic energy dissipated for the Northridge 1994 earthquake 


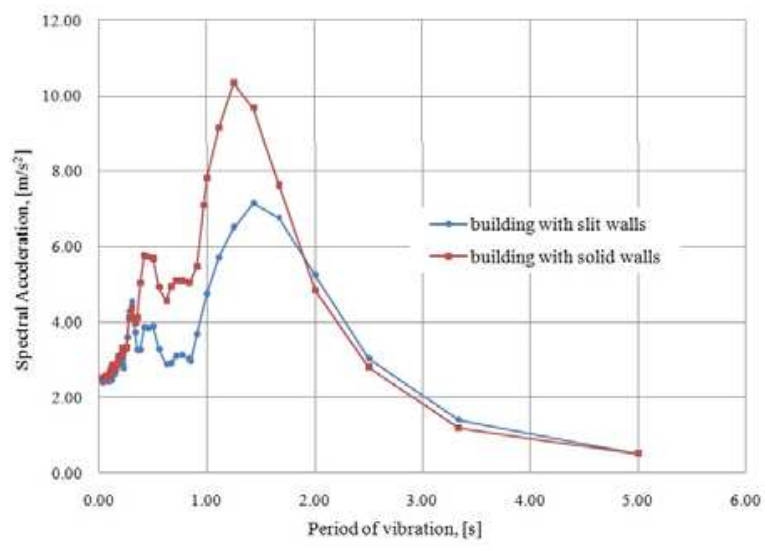

Fig. 30. Spectral acceleration of the proposed buildings for the Vrancea 1977 N-S earthquake, $\mathrm{PGA}=0.2 \mathrm{~g}$

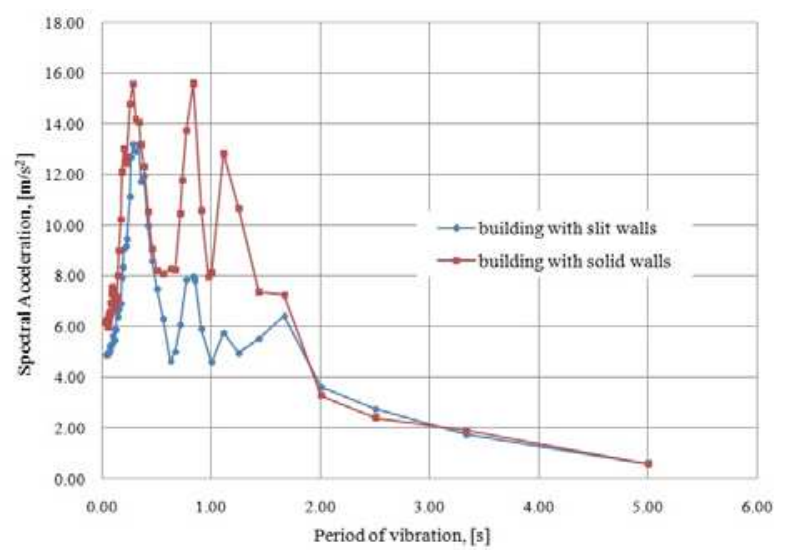

Fig. 32. Spectral acceleration of the proposed buildings for the Northridge 1994 earthquake,

\section{$\mathrm{PGA}=0.4 \mathrm{~g}$}

In order to see the influence of the peripheral walls on the entire building, Fig. 34 shows the comparison between the hysteresis energy dissipated by the buildings and by the solid and slit walls. The energy dissipated by the walls was evaluated by Baetu el al. (2014).

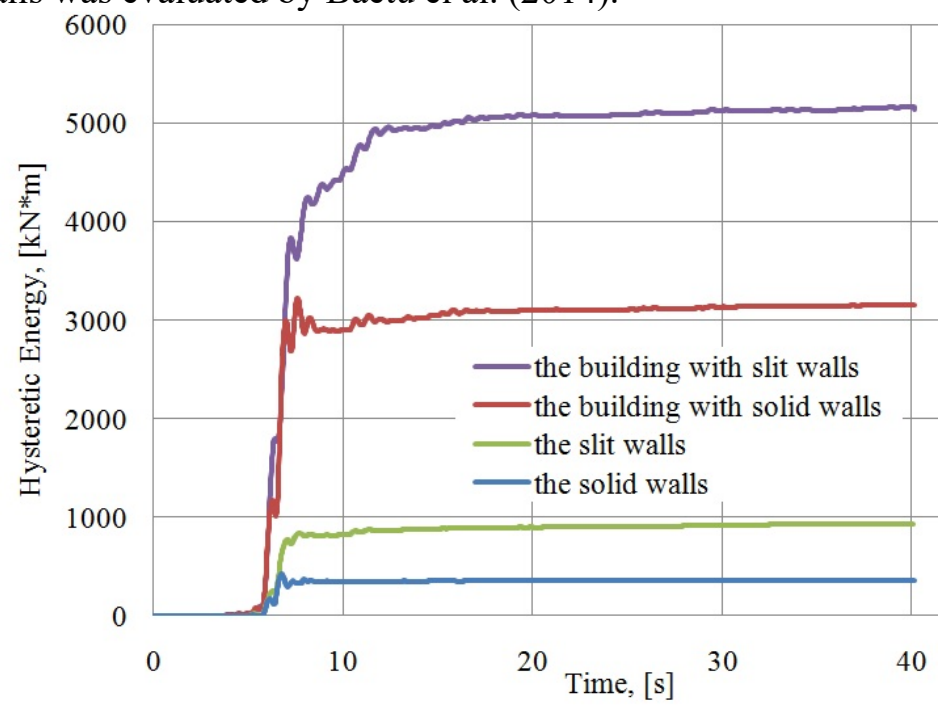

Fig. 34. Comparison between hysteresis energy dissipated by the buildings and by the solid and slit walls for the Vrancea $1977 \mathrm{~N}-\mathrm{S}$ earthquake, $\mathrm{PGA}=0.2 \mathrm{~g}$ 
The results obtained for the variations of DI with PGA, the hysteretic energy and the displacement at the roof level for the buildings and the walls, are compared in the figures 35-40 with the results obtained for walls by Baetu el al. (2014).

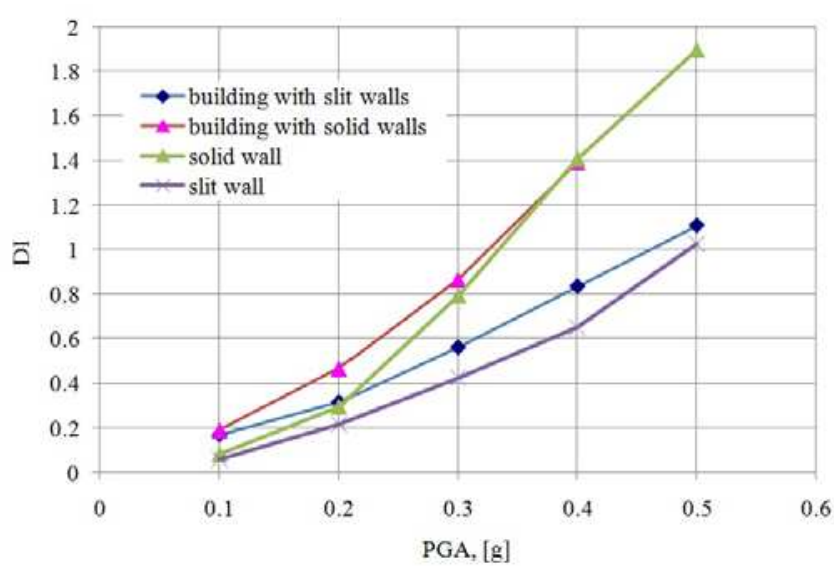

Fig. 35. Comparison of the variation of DI with PGA for the Vrancea $1977 \mathrm{~N}-\mathrm{S}$ earthquake, for the buildings studied herein and the walls studied by Baetu et al. (2014)

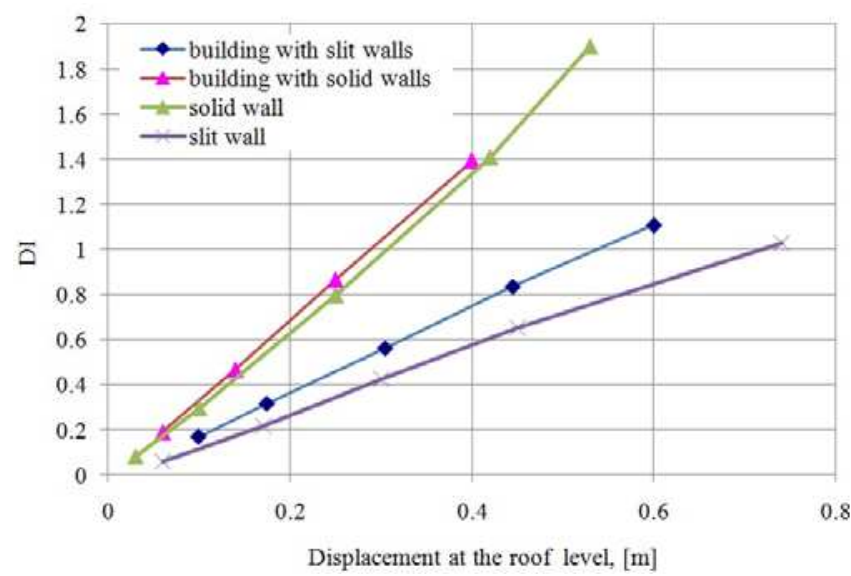

Fig. 37. Comparison of the variation of DI with the displacement at the roof level for the Vrancea 1977 $\mathrm{N}-\mathrm{S}$ earthquake, for the buildings studied herein and the walls studied by Baetu et al. (2014)

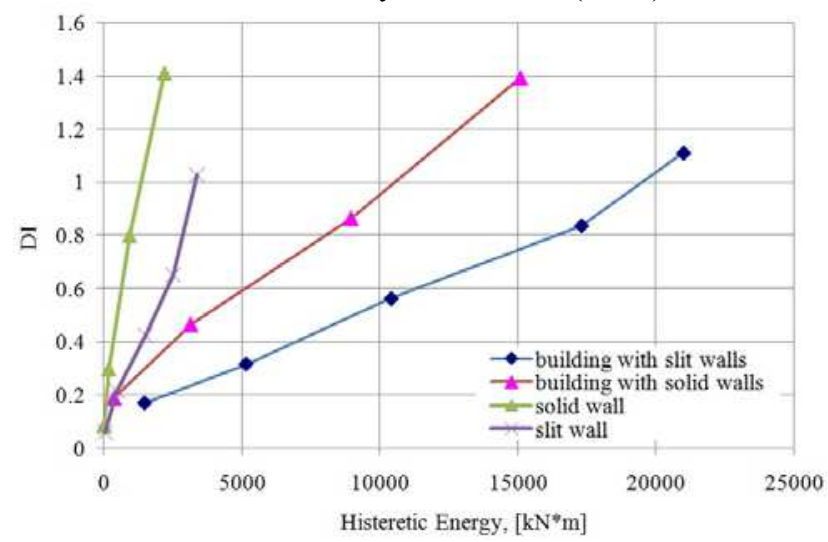

Fig. 39. Comparison of the variation of DI with the hysteretic energy for the Vrancea $1977 \mathrm{~N}-\mathrm{S}$ earthquake, for the buildings studied herein and the walls studied by Baetu et al. (2014)

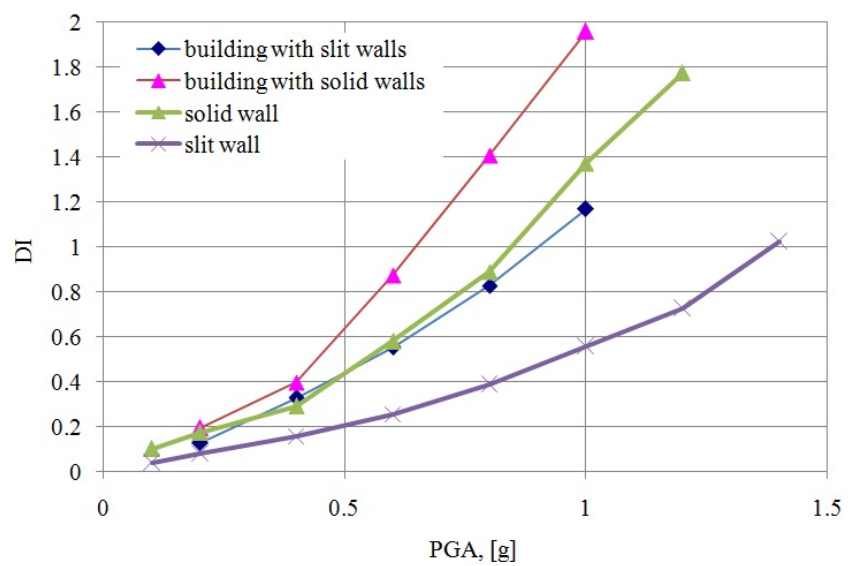

Fig. 36. Comparison of the variation of DI with PGA for the Northridge 1994 earthquake, for the buildings studied herein and the walls studied by Baetu et al.

(2014)

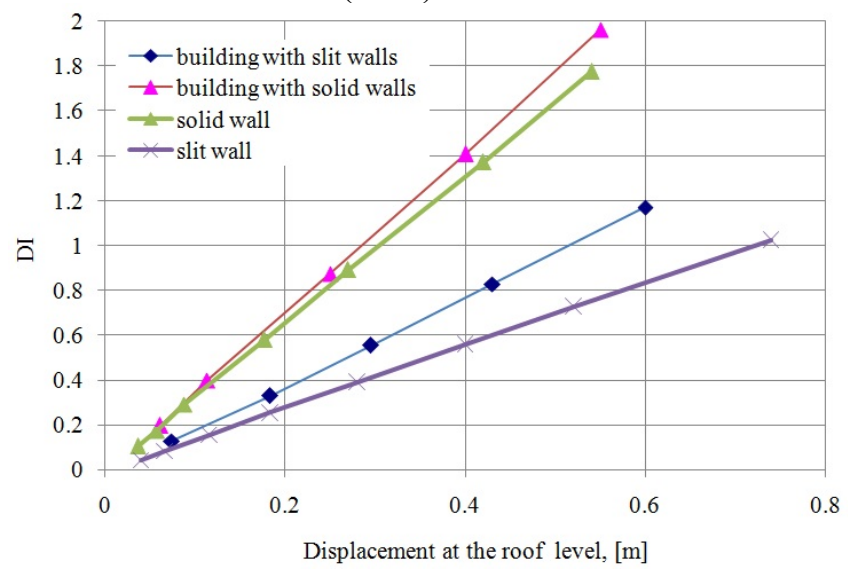

Fig. 38. Comparison of the variation of DI with the displacement for the Northridge 1994 earthquake, for the buildings studied herein and the walls studied by Baetu et al. (2014)

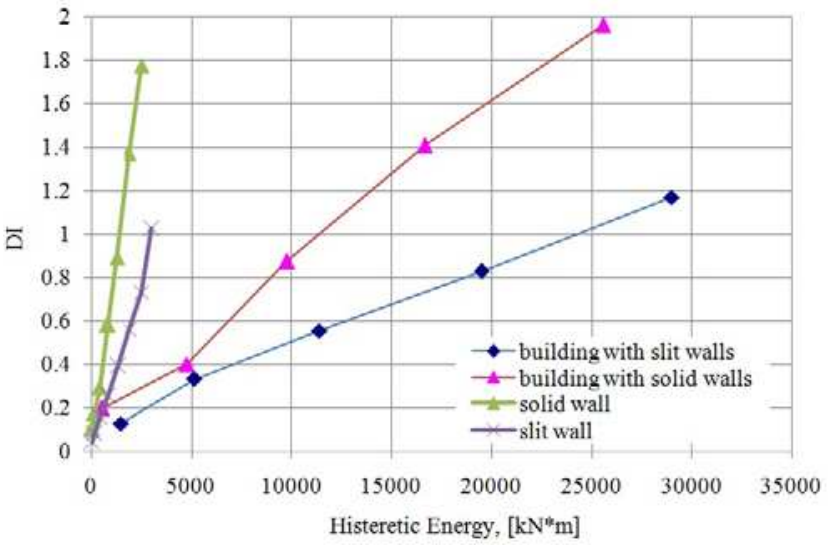

Fig. 40. Comparison of the variation of DI with the hysteretic energy for the Northridge 1994 earthquake, for the buildings studied herein and the walls studied by Baetu et al. (2014)

\section{Discussions of the results}


The non-structural and structural damage limitation performance objective of buildings is achieved by limiting their overall lateral displacements to levels acceptable for the integrity of all their parts. To achieve these performance levels, a structure should have a high stiffness for low intensity earthquakes and a low stiffness with high ductility for high intensity earthquakes. Accordingly, slit walls are ideal elements for designing buildings in seismic areas, because they have high initial stiffness and low final stiffness with high ductility.

The comparisons between the two studied buildings with slit and solid walls reveal that they have a quite different behaviour. From the results obtained for the Vrancea, 1977, N-S earthquake, we can see in Fig. 24 that the building with solid wall fails before the building with slit wall. The building with solid walls fails at a PGA of approx. $0.35 \mathrm{~g}$, while the building with slit walls fails at a PGA of approx. $0.45 \mathrm{~g}$. Fig. 25 shows how much hysteretic energy is dissipated by the two buildings until reaching the collapse level. It is clear that the building with slit wall dissipates more hysteretic energy at every level of damage. Beyond the repair level, the building with slit walls dissipates approx. $7000 \mathrm{kN} \times \mathrm{m}$ hysteretic energy and the building with solid walls dissipates only approx. $2500 \mathrm{kN} \times \mathrm{m}$ hysteretic energy; at collapse level, the building with slit walls dissipates approx. $20000 \mathrm{kN} \times \mathrm{m}$ hysteretic energy and the building with solid walls dissipates only approx. $10000 \mathrm{kN} \times \mathrm{m}$ hysteretic energy, which is the half when compared with the building with slit walls. For a value of approx. $10000 \mathrm{kN} \times \mathrm{m}$ of dissipated hysteretic energy, the building with slit wall crosses the repair level and the solid wall collapses. From the results obtained for the Northridge 1994 earthquake, we can see in Fig. 28 that the building with solid walls fails before the building with slit walls. The building with solid walls fails at a PGA of $0.4 \mathrm{~g}$, while the building with slit walls fails at a PGA of approx. $0.45 \mathrm{~g}$. Fig. 29 shows that the building with slit walls dissipates more hysteretic energy at every level of damage. Beyond the repair level, the building with slit walls dissipates approx. $7500 \mathrm{kN} \times \mathrm{m}$ hysteretic energy and the building with solid walls dissipates only approx. $5000 \mathrm{kN} \times \mathrm{m}$ hysteretic energy; at collapse level, the building with slit walls dissipates approx. $25000 \mathrm{kN} \times \mathrm{m}$ hysteretic energy and the building with solid walls dissipates only approx. $10000 \mathrm{kN} \times \mathrm{m}$ hysteretic energy.

When a short connection of the slit wall starts failing, the stiffness of the wall and also the stiffness of the building begins to decrease and the top displacement increases. This behaviour does not increase the seismic vulnerability of the buildings with slit wall because, as we can see in the figures 26 and 27, the damage index has low values. At the collapse level, the displacement of the building with slit walls is of approx. $0.55 \mathrm{~m}$ and for the building with solid walls it is of approx. $0.3 \mathrm{~m}$ for both earthquakes considered in the analysis. It follows that, for the same displacement, the damage index is very different; for example, at a displacement of $0.3 \mathrm{~m}$, the building with slit wall has a DI equal to 0.55 and it is beyond the repair level while the solid wall has a DI equal to 1 and it is at collapse level. In the figures 26 and 27 an almost linear relation is observed between the top displacement and the DI. In order to explain this fact, we have split the Park \&Ang relation and calculated each term separately in order to see with which percent they contribute to the final value. The conclusion is that the first term $\frac{\delta_{m}}{\delta_{u}}$ has a weight of $80 \%$ and the second term $\frac{\beta}{\delta_{u} P_{y}} \int d E_{h}$ has a weight of $20 \%$. The second term is smaller because it is influenced by the $\beta=0.1$ parameter and $P_{y}$ which is the yield strength in the idealized curve.

Analyzing the figures 22 and 23, we observe that the Northridge 1994 earthquake has a lower effect on the studied buildings than the Vrancea $1977 \mathrm{~N}-\mathrm{S}$ earthquake. It can be seen that after the connections start to fail at a PGA of $0.4 \mathrm{~g}$, the hysteresis energy dissipated by the building with slit walls is close to the one dissipated by the building with the solid walls.

The nonlinear response of the buildings with reinforced concrete structural walls is accompanied by a decrease of stiffness and an increase of damping up to a certain level of damage. By increasing the damping, the effects of the ground motion is reduced. After the failure of the short connections, the buildings with slit walls have a damping value bigger than the building with solid walls. The damping increase is originated by the fact that, after the connections failure, the wall becomes more flexible. Figures 30 and 32 also show that after the connections fail the spectral acceleration decreases due to the hysteretic damping increase and to the structure period increase. As we can see in Figures 30 and 32, the spectral acceleration of the building with slit walls have lower values than that of the building with solid wall after the failure of the short connections for both the Vrancea $1977 \mathrm{~N}-\mathrm{S}$ earthquake for a PGA=0.2g and the Northridge 1994 earthquake for a $\mathrm{PGA}=0.4 \mathrm{~g}$. This means that the seismic forces are smaller for the building with slit wall and an economical design is possible. To capture the behaviour of the building with slit walls after the short connections fails, a 
PGA of $0.2 \mathrm{~g}$ was selected for the Vrancea $1977 \mathrm{~N}-\mathrm{S}$ earthquake. Fig. 31 shows that the short connections fail after the fifth second of the seismic ground motion, once occurred the main shock and when the behaviour of the slit wall changes. Similar results were obtained in the case of the same building but analyzed for the Northridge 1994 earthquake (Fig. 33). The stiffness of the slit wall decreases and the natural period increases.

Fig. 34 shows very clearly that the difference between the hysteretic energy dissipated by the buildings $(2000 \mathrm{kNm})$ is higher that the difference between the hysteretic energy dissipated by the walls (almost $500 \mathrm{kNm}$ ), for the Vrancea $1977 \mathrm{~N}-\mathrm{S}$ earthquake, $\mathrm{PGA}=0.2 \mathrm{~g}$. This means that the slit walls contribute with only $500 \mathrm{kNm}$ to the dissipated energy and the rest is dissipated by the frames. Thus, slit walls help that buildings dissipate more energy. When a high intensity seismic event occurs, slit walls split in two along the slit zone and their stiffness and strength decrease very fast. This phenomenon applies higher seismic forces upon the frames of the buildings resulting in ductile behaviour of the entire building.

Fig. 35 shows,for the Vrancea 1977 N-S earthquake,the variation of DI with PGA for the buildings studied herein and compares it with that obtained for the walls studied by Baetu et al. (2014); it can be seen that the damage indices for the building with solid walls and for the solid walls have similar pattern of variation. Similar results can be seen in the case of the building with slit walls and the slit wall. These comparisons show that the behaviour of both buildings is controlled by the peripheral walls, and the building fails at the same PGA as the peripheral walls. In the case of the Vrancea earthquake, these similar patterns of variation are due to the failure of some elements or short connections which produce the increase of the natural period of the building and of the wall. Thus, the natural period of the buildings is $1.077 \mathrm{~s}$, the natural period of the walls is $0.715 \mathrm{~s}$ and the predominant period of Vrancea earthquake is $1.6 \mathrm{~s}$. In the case of the Northridge earthquake, the variation of the damage index with the PGA has a different pattern (Fig. 36) because the walls and the buildings are never close to resonance due to the fact that the predominant period of the Northridge earthquake is $0.7 \mathrm{~s}$, below the periods of the buildings and of the walls. In this case, the walls and the buildings fail at different PGA values. In the case of the studied buildings and walls, similar aspects were also observed in the case of the variation of the DI in function of the displacement at the roof level for the Vrancea 1977 N-S earthquake (see Fig. 37) and for the Northridge 1994 earthquake (see Fig. 38). The comparison of the variation of the DI in function of the hysteretic energy for the Vrancea $1977 \mathrm{~N}-\mathrm{S}$ earthquake (Fig. 39) and for the Northridge 1994 earthquake (Fig. 40) shows that, for damage index below 0.2 , the hysteretic energy dissipated has close values, but, after the short connections fail and the walls begin to crack at the base, this differences increase.

\section{Conclusions}

The objective of this article is to investigate the effectiveness of the proposed slit wall solution in increasing the energy dissipation in reinforced concrete high-rises buildings with structural walls. Slit zones are inserted on the height of the structural walls of buildings and five short connections are introduced in the slits. The proposed solution changes the behaviour of the building with solid walls providing more ductility, energy dissipation and a better crack pattern. When the short connections behave elastically, the initial stiffness of the building with slit walls is close to that of the building with solid wall but, when the short connections develop large cracks or fail, the wall stiffness decreases rapidly, without developing large cracks at the base and, at the same time, the overall stiffness of the building decreases. A nonlinear dynamic analysis of the buildings has been performed by using SAP2000 and a layered model for structural walls, while the short connections were simulated with a hysteretic pivot model. The hysteretic force-displacement curve corresponding to the short connections is obtained using a series of hysteretic rules for loading and unloading. The model used in this analysis is simple and was developed by the authors in order to use low processing resources and to reduces processing time for a complex dynamic analysis. Such a simple model was necessary because multiple dynamic analyses varying the PGA were performed in order to obtain damage curves. Using the nonlinear dynamic analysis results, the damage evaluation of the walls was based on the Park\&Ang damage index.

Comparative studies between the buildings with slit and solid walls allow concluding that:

- From the pushover curves for both analyzed buildings, it can be seen that the building with solid walls has a brittle failure while the building with slit walls has a ductile failure.

- For the same displacement, the damage index DI is very different in the two cases.

- The building with slit walls dissipates more hysteretic energy than the building with solid wall. This occurs because the slit wall has a better hysteretic energy dissipation capacity and dissipates seismic energy by cracks extended on the entire surface of the wall and by the crush 
of the shear connections, while the solid wall dissipates seismic energy only by large cracks at the base of the wall.

- The damping increases in the case of the slit wall after the failure of the short connections and the spectral acceleration is reduced, the seismic forces being thus also reduced, allowing an economical design.

- After the failure of the short connections, the slit wall stiffness decreases and the natural period increases, in this way being avoided the resonance phenomenon.

- The slit walls help the building to dissipate more energy because, when a high intensity seismic event occurs and the connections fail, the slit walls stiffness and strength decrease, transmitting more seismic force into the frames, resulting a ductile behaviour of the entire building.

- The displacement and the hysteretic energy dissipated by the walls and by the buildings show that the behaviour of the studied buildings is controlled by the peripheral walls.

\section{Acknowledgements}

This work was done with financial support from the European Union under Project EURODOC POSDRU 88/1.5./S/59410, during the six month internship at the Polytechnic University of Cataluña from Barcelona, Spain. It has been also partially sponsored by the European Commission (project DESURBSFP7-2011-261652) and by the Ministry of Education and Science of Spain, project "Enfoque integral y probabilista para la evaluación del riesgo sísmico en España, CoPASRE” (CGL2011-29063).

\section{References}

Băetu, S. (2013), Structures with dissipative walls, Publisher "Matei-Teiu Botez", Iassy, Romania. (in Romanian)

Băetu, S., Bărbat, A.H., Ciongradi, I. (2014), Seismic damage evaluation of reinforced concrete slit walls, Engineering Computations, ISSN: 0264-4401, accepted in 22 May 2014.

Băetu, S., Ciongradi, I. (2011), Nonlinear analysis models of the reinforced concrete structural walls, Proceedings of International Conference DEDUCON - Sustainable Development in Civil Engineering, Iasi, Vol. 1, pp. A66-A83.

Băetu, S., Ciongradi, I. (2012), Nonlinear finite element analysis of reinforced concrete slit walls with ANSYS (II), Bulletin of the Polytechnic Institute of Iasi, Construction and Architecture section, Vol. LVIII No. 1, pp. 99-111.

Băetu, S., Ciongradi, I., Văsieş, G. (2010), Static nonlinear analysis of structural reinforced concrete walls energy dissipaters with shear connections, "Computational Civil Engineering 2010”, International Symposium, Iasi, Romania.

Barbat A.H. and Bozzo, L.M. (1997), "Seismic analysis of base isolated buildings", Archives of Computational Methods in Engineering, 4(2), 153-192.

Barbat, A. H., Carreño, M. L., Cardona, O. D. and Marulanda, M. C. (2011), "Evaluación holística del riesgo sísmico en zonas urbanas", Revista internacional de métodos numéricos para cálculo y diseño en ingeniería, 27(1), 3-27.

Barbat, A. H., Carreño, M. L., Pujades, L. G., Lantada, N., Cardona O. D. and Marulanda, M. C. (2010), Seismic vulnerability and risk evaluation methods for urban areas. A review with application to a pilot area, Structure and Infrastructure Engineering, 6, 1-2, 2010, 17-38.

Barbat, A. H., Pujades, L. G., Lantada N. and Moreno, R. (2006), Performance of buildings under earthquakes in Barcelona, Spain, Computer-Aided Civil and Infrastructure Engineering, 21, 573-593.

Belarbi, A., Prakash, S.S. (2009), Assessment of performance-based design approach for RC bridge columns under combined loadings using damage index models, SBEIDCO - $1^{\text {st }}$ International Conference on Sustainable Built Environment Infrastructure in Developing Countries, Oran, Algeria, pp. 33-40.

Code for seismic design of buildings P100-1/2006. (in Romanian)

Code for the design of buildings with reinforced concrete structural walls CR 2-1-1.1-2005. (in Romanian)

Egozcue, J.J., Barbat, A.H., Canas, J.A., Miquel J. and Banda, E. (1991), “A method to estimate occurrence probabilities in low seismic activity regions”, Earthquake Engineering and Structural Dynamics, 20(1), 43-60. 
Faleiro, J., Oller S. and Barbat, A. H. (2008), Plastic-damage seismic model for reinforced concrete frames, Computers and Structures, 86(7-8), 581-597.

Ghosh, S., Datta, D., Katakdhond, A.A. (2011), Estimation of the Park-Ang damage index for planar multi-storey frames using equivalent single-degree systems, Engineering Structures, Vol. 33, pp. 2509-2524.

http://peer.berkeley.edu/nga/search.htm, 01.08.2014

http://www.incerc2004.ro/accelerograme.htm, 01.08.2014

Kachlakev, D., Miller, T., Yim, S. (2001), Finite Element Modelling of Reinforced Concrete Structures Strengthened with frp Laminates, Final Report SPR 316, Oregon Department of Transportation, USA.

Kwan, A.K.H., Dai, H., Cheung, Y.K. (1999), Non-linear sesimic responce of reinforced concrete slit shear walls, Journal of Sound and Vibration, Vol. 226 No. 4, pp. 701-718.

Lantada, N., Pujades L.G. and Barbat, A.H. (2009), "Vulnerability index and capacity spectrum based methods for urban seismic risk evaluation. A comparison", Natural Hazards, 51, 501-524.

Lepage, A., Neuman, S.L., Dragovich, J.J. (2006), Practical modelling for nonlinear seismic response of RC wall structures, 8th National Conference on Earthquake Engineering, San Francisco, California, April 18-22.

Miao, Z.W., Lu, X.Z., Jiang, J.J., Ze, L.P. (2006), Nonlinear FE model for RC shear walls based on multi-layer shell element and microplane constitutive model, Computational methods in engineering and science, Hainan, China.

Martinez, X. Oller, S. Rastellini, F. and Barbat, A.H. (2008), “A numerical procedure simulating RC structures reinforced with FRP using the serial/parallel mixing theory”, Computers \& Structures, 86, 1604-1618.

Oller S. and Barbat, A. H. (2006), Moment-curvature damage model for bridges subjected to seismic loads, Computer Methods in Applied Mechanics and Engineering, 195, 4490-4511.

Park, Y.J., Ang, A.H.S. (1985), Seismic damage analysis of reinforced concrete buildings, Journal of Structural Engineering, Vol. 111 No. 4, pp. 740-757.

Paulay, T., Priestley, M. J. N. (1992), Seismic design of reinforced concrete and masonry buildings, John Wilei \& Sons Inc., New York.

Sap2000 V14 Help (2009), Computers and Structures Inc., Berkeley, California, USA.

Valles, R.E., Reinhorn, A.M., Kunnath, S.K., Madan, A. (1996), IDARC 2D Version 4.0: A program for inelastic damage analysis of buildings, Tehnical Report NCEER-96-0010, State University of New York at Buffalo.

Vera Oyarzo, C. (2006), Damage evaluation in RC shear walls using the damage index of Park\&Ang, First European Conference on Earthquake Engineering and Seismology, Geneva, Switzerland.

Vielma, J.C., Barbat, A.H., Oller, S. (2009), Seismic performance of waffled-slabs floor buildings, Structures and Buildings (Proceedings of the Institution of Civil Engineering), Vol. 162 No. SB3, pp. 169-182.

Vielma, J.C., Barbat, A.H., Oller, S. (2010), Seismic safety of limited ductility buildings, Bulletin of Earthquake Engineering, Vol. 8 No.1, pp. 135-155.

Seismic evaluation and retrofit of concrete buildings ATC40, Applied technology council, California 94065 USA.

Development of Guidelines for Seismic Rehabilitation of Buildings - Phase 1: Issues Identification and Resolution, FEMA 237, Federal Emergency Management Agency, Washington DC, USA.

Gedik, Y.H., Nakamura, H., Ueda, N., Kunieda, M. (2011), A new stirrup design considering 3-D effects in short deep beams, The twelfth East Asia-Pacific Conference on Structural Engineering and Constructions, Procedia Engineering, Vol. 14, pp. $2964-2971$.

Zhao, Z.Z., Kwan, A.K.H., He, X.G. (2004), Nonlinear finite element analysis of deep reinforced concrete coupling beams, Engineering Structures, Vol. 26, pp. 13-25. 